\title{
Ontogenetic development of the shoulder joint muscles in frogs (Amphibia: Anura) assessed by digital dissection with implications for interspecific muscle homologies and nomenclature
}

\author{
Karolin Engelkes $^{1}$ D $\cdot$ Supak Panpeng ${ }^{1} \cdot$ Alexander Haas $^{1}$ (D)
}

Received: 18 September 2020 / Revised: 10 November 2020 / Accepted: 19 November 2020 / Published online: 16 February 2021

(c) The Author(s) 2021

\begin{abstract}
Previous myological studies show inconsistencies with regard to the identification and naming of the shoulder joint muscles in frogs and toads (Amphibia: Anura). Those inconsistencies were revealed and resolved by assessing the ontogenetic development, innervation, and adult morphology of selected anuran species representing ancient lineages and two major neobatrachian groups. To do so, digital dissections of volumes acquired by histological serial sectioning, episcopic microtomy, and contrast-enhanced micro-computed tomography scanning were performed and three-dimensional reconstructions were derived. Muscle units crossing the shoulder joint were defined, their ontogenetic development was described, their homology across species was established, and a consistent nomenclature was suggested. The $\mathrm{mm}$. anconaeus, dorsalis scapulae, latissimus dorsi, and the group of scapulohumeralis muscles were ontogenetically derived from the dorsal pre-muscle mass present in all tetrapods. The ventral pre-muscle mass gave rise to the $\mathrm{mm}$. cleidohumeralis, episternohumeralis, supracoracoideus, coracoradialis, subcoracoscapularis, coracobrachialis, and pectoralis. The results indicate that the $\mathrm{mm}$. anconaeus, dorsalis scapulae, latissimus dorsi, coracoradialis, and the portionis sternalis and abdominalis of the $\mathrm{m}$. pectoralis have consistently been recognized and denoted in previous studies, whereas the names for the muscle units commonly denoted as m. coracobrachialis longus and as parts of the m. deltoideus are misleading with regard to the ontogenetic origin of these muscles. The $\mathrm{mm}$. scapulohumeralis profundus anterior and posterior, although present, have been overlooked in some studies. The $\mathrm{mm}$. cleidohumeralis, supracoracoideus, and coracobrachialis are present with two parts or portions in some species, these portions have previously not always been recognized and assigned correctly.
\end{abstract}

Keywords Homology $\cdot$ Metamorphosis $\cdot$ Myology $\cdot$ Muscle nomenclature $\cdot$ Ontogeny $\cdot$ Synonym

\section{Introduction}

The morphologies of the pectoral fins of fishes and of the forelimbs of tetrapods, as well as of the pectoral girdle that connects them to the axial skeleton, have long received attention to establish the homology of the anatomical elements across vertebrates and to understand the evolutionary transformations of fins into limbs and of limbs within tetrapods (e.g., Gegenbaur 1865; Rolleston 1869; Romer 1924; Diogo et al. 2016; Molnar et al. 2018). The evolution and resulting homologies of the skeletal elements of the

Karolin Engelkes

karolin.engelkes@uni-hamburg.de

1 Center of Natural History (CeNak), Universität Hamburg, Hamburg, Germany pectoral girdle and forelimbs are comparably well known and supported by the fossil record (e.g., McGonnell 2001; Coates et al. 2002; Shubin et al. 2006, 2009; Ponomartsev et al. 2017), whereas the related soft tissues have rarely been considered (Soliz et al. 2018; but see, e.g., Rolleston 1869, Romer 1922, and Abdala and Diogo 2010 for attempts to assess forelimb muscle homologies across tetrapods and Diogo et al. 2016 and Molnar et al. 2018 for the reconstruction of muscle evolution across the fin-to-limb transition).

It is striking that extant amphibians are represented by a caudate species in most of the studies investigating the evolution and homology of anatomical elements of the forelimb and pectoral girdle within vertebrates (e.g., Romer 1922; Diogo and Abdala 2007; Molnar et al. 2018; but see Abdala and Diogo 2010 for the inclusion of an anuran species). It should be kept in mind, however, that the independent evolutionary history of the Caudata is as long as the one 
of the Anura, because both taxa are considered to be sister groups (e.g., Jetz and Pyron 2018; also see the discussion on "basal" or "ancestral" species in, e.g., Krell et al. 2004, Omland et al. 2008, and Zachos 2016). Consequently, it is likely that derived (i.e., apomorphic) character states have evolved within the Caudata if compared to the last common ancestor of the Anura and Caudata. The reconstruction of the evolution of the forelimbs could therefore benefit from the inclusion of the Anura by contributing to the assessment of muscle character states in the last common ancestor of Anura and Caudata.

Having reassessed existing descriptions of the shoulder joint muscles in different anuran species, we observed inconsistencies in the identification of muscle units and in the use of muscle names. Ritland (1955), for example, synonymized his 'supracoracoideus superficialis' with the term 'pectoralis portio epicoracoidea' utilized by Gaupp (1896) and thereby implied the homology of the corresponding muscle units. Diogo and Ziermann (2014), in contrast, reported the presence of both, a pars epicoracoidea of the $\mathrm{m}$. pectoralis and a separate $\mathrm{m}$. supracoracoideus, which contradicts the homology assumption by Ritland (1955). Jones (1933) observed the presence of a $\mathrm{m}$. supracoracoideus profundus in, among others, two bufonid species, whereas Bigalke (1927) reported no such muscle in Bufo bufo (then B. vulgaris) but a pars superficialis of the $\mathrm{m}$. coraco-brachialis brevis that remarkably resembled the $\mathrm{m}$. supracoracoideus profundus in Jones (1933). The m. scapulohumeralis profundus anterior was observed in various anuran species, including representatives of the Ranidae (Tyson 1987). In a different study (Gaupp 1896), however, no such muscle was reported in species of the genus Rana. Likewise, the $\mathrm{m}$. scapulohumeralis profundus posterior was observed in various species, including representatives of the Hyloidae and Ranidae (Tyson 1987), but in other studies, this muscle was neither included in a list of pectoral girdle muscles in hylid anurans, nor described in Rana (Soliz et al. 2018; Gaupp 1896, respectively).

The inconsistencies noted above make the homologization of shoulder joint muscles across anuran species challenging and obstruct the reconstruction of the character states in the last common ancestor of the Anura. The latter, however, would help to establish muscle homologies between the Anura and the Caudata, and to fit both taxa within the larger picture of the evolution of limbs.

The primary aim of the present study was to identify the muscle units occurring in the shoulder joint of anurans and to establish their interspecific homologies. To do so, the ontogenetic development and innervation of the shoulder joint muscles were assessed in three anuran species representing one ancient lineage (Bombinatoridae: Bombina orientalis (Boulenger, 1890)) and the two major neobatrachian groups (Ranoidea: Ranidae: Rana temporaria Linnaeus,
1758; Hyloidea: Bufonidae: Rhinella marina (Linnaeus, 1758)). In addition, previously published descriptions of the shoulder joint muscles in selected species (various species of Rana in Gaupp 1896; Bufo bufo (Linnaeus, 1758) in Bigalke 1927; Ascaphus truei Stejneger, 1899 in Ritland 1955) were reassessed to identify inconsistencies in the use of muscle names and to suggest a consistent nomenclature. The descriptions by Gaupp (1896) were included, because they seem to be the most frequently referenced for anuran muscle anatomy; the nomenclature introduced by him, and modified versions of it, presumably are the most widely used (compare, e.g., Bigalke 1927; Jones 1933; Mahendra 1936; Ritland 1955; Burton 1983; Duellman and Trueb 1994; Manzano et al. 2008; Baleeva 2009). The works of Ritland (1955) and Bigalke (1927) were used for comparison as they provide thorough descriptions of the muscles in species belonging to an ancient anuran linage and the Hyloidea, respectively, and because both refer to the nomenclature of Gaupp (1896).

\section{Materials and methods}

\section{Specimens and usages}

A total of 11 larvae (Table 1) ranging from Stage 32 to Stage 41 (staging after Gosner 1960) of Bombina orientalis, Rana temporaria, and Rhinella marina were used to investigate the ontogenetic development and innervation of the shoulder joint muscles by histological serial sectioning and three-dimensional (3d) reconstruction. A pre-existing dataset of Alytes obstetricans (Laurenti, 1768) (ZMH A12442) acquired by episcopic microtomy (Engelkes et al. 2018) served as source of data for that species, but was also modified and transformed into a hypothetical, schematic anatomical $3 \mathrm{~d}$ model that illustrates all identified muscle units, their spatial relationships, and their innervations. Contrast-enhanced micro-computed tomography $(\mu \mathrm{CT})$ volumes of adult specimens of Bufo bufo (ZMH A04660), Rhinella marina (ZMH A15443), and Ascaphus truei (UF H 80664; downloaded from MorphoSource, Duke University) were examined. Furthermore, histological serial sections from the ZMH museum collection of a late metamorphic stage of $A$. truei (ZMH A09807, Stage 42) were included. The latest larval stages examined and, if available, adult specimens of each exemplar species were used to reassess previously published anatomical descriptions (Gaupp 1896; Bigalke 1927; Ritland 1955) of those or closely related (Pyron and Wiens 2011) species. Specimens that were sectioned for this study were deposited at the ZMH collection (Table 1). 
Table 1 Specimens, developmental stage, and methods

\begin{tabular}{|c|c|c|c|}
\hline $\begin{array}{l}\text { Specimen } \\
\text { (collection number) }\end{array}$ & Developmental stage & Method & Remark \\
\hline Alytes obstetricans (ZMH A12442) & Subadult/adult & Episcopic microtomy & dataset from Engelkes et al. (2018) \\
\hline Ascaphus truei (UF H 80664) & Adult & $\mu \mathrm{CT}$ & $\begin{array}{l}\text { iodine stained; volume downloaded from Morpho- } \\
\text { Source; https://doi.org/10.17602/M2/M22469 }\end{array}$ \\
\hline Ascaphus truei (ZMH A09807) & 42 & Histology & https://doi.org/10.25592/uhhfdm.1754 \\
\hline Bombina orientalis (ZMH A12427) & 32 & Histology & https://doi.org/10.25592/uhhfdm.1768 \\
\hline Bombina orientalis (ZMH A12429) & 35 & Histology & https://doi.org/10.25592/uhhfdm.1770 \\
\hline Bombina orientalis (ZMH A12435) & 41 & Histology & https://doi.org/10.25592/uhhfdm.1772 \\
\hline Bufo bufo (ZMH A04660) & Adult & $\mu \mathrm{CT}$ & $\begin{array}{l}\text { unstained and iodine stained; unstained scan } \\
\text { published in Engelkes et al. (2020); https:// } \\
\text { doi.org/10.25592/uhhfdm.1188, https://doi. } \\
\text { org/10.25592/uhhfdm. } 1788\end{array}$ \\
\hline Rana temporaria (ZMH A14736) & $32-33$ & Histology & https://doi.org/10.25592/uhhfdm.1824 \\
\hline Rana temporaria (ZMH A14739) & 34 & Histology & https://doi.org/10.25592/uhhfdm.1826 \\
\hline Rana temporaria (ZMH A14740) & 35 & Histology & https://doi.org/10.25592/uhhfdm.1828 \\
\hline Rana temporaria (ZMH A12870) & 41 & Histology & https://doi.org/10.25592/uhhfdm.1822 \\
\hline Rhinella marina (ZMH A14928) & $32-33$ & Histology, $3 \mathrm{~d}$ reconstruction & https://doi.org/10.25592/uhhfdm.1830 \\
\hline Rhinella marina (ZMH A14930) & 34 & Histology, 3d reconstruction & https://doi.org/10.25592/uhhfdm.1832 \\
\hline Rhinella marina (ZMH A14933) & 37 & Histology, $3 \mathrm{~d}$ reconstruction & https://doi.org/10.25592/uhhfdm.1834 \\
\hline Rhinella marina (ZMH A14937) & 41 & Histology, 3d reconstruction & https://doi.org/10.25592/uhhfdm.1836 \\
\hline Rhinella marina (ZMH A15443) & Adult & $\mu \mathrm{CT}$ & iodine stained; https://doi.org/10.25592/uhhfdm.1838 \\
\hline
\end{tabular}

Staging after Gosner (1960). UF: Florida Museum of Natural History; ZMH: Zoologisches Museum Hamburg

\section{Histology}

Larval specimens selected for histological serial sectioning were decalcified and embedded in either Paraplast Plus ${ }^{\circledR}$ (Leica Biosystems) or Roti ${ }^{\circledR}$-Plast with DMSO (Carl Roth $\mathrm{GmbH}+\mathrm{Co} . \mathrm{KG})$. The resulting blocks were sectioned on a rotatory microtome (Microm ${ }^{\mathrm{TM}} \mathrm{HM} 340 \mathrm{E}$; Microm International $\mathrm{GmbH}$ ) with slice thicknesses between 6 and $10 \mu \mathrm{m}$. Sections were mounted on glass slides and stained according to an Azan staining protocol (modified from Zbären 1966; 2-3 min staining in Kernechtrubin, 5-7 min differentiation in 5\% phosphotungstic acid, 6-15 min staining in aniline blue-orange G, 4-5 min differentiation in 96\% ethanol; staining durations were dynamically adjusted as needed).

The histological sections of the pectoral girdle region were digitized with a digital microscope (Leica DM6000 B; Leica Microsystems $\mathrm{GmbH}$ ) and edited (adjustment of brightness and contrast, sharpness, and canvas size) in Fiji (based on ImageJ version 1.51n; Schindelin et al. 2012; Schneider et al. 2012). Depending on the quality of the original series of histological sections, the digital image stacks were either rigidly aligned in Amira ${ }^{\circledR}$ (version 6.0.1; KonradZuse-Zentrum Berlin, FEI Visualization Sciences Group) or aligned in the Fiji plugin TrakEM2 allowing for affine or elastic transformations (Cardona et al. 2012). The resulting aligned volumes were converted to 8-bit grayscale images.

\section{Episcopic microtomy}

The generation of the previously published dataset of episcopic images of Alytes obstetricans (ZMH A12442) was described in detail in Engelkes et al. (2018); in short, the procedure was as follows: The specimen was decalcified and impregnated with lead ions followed by Paraplast Plus ${ }^{\circledR}$ embedding. Fiducial points were induced into the block to improve the image alignment quality in consecutive processing steps. Sections of $10 \mu \mathrm{m}$ thickness were cut of the block surface using a rotatory microtome (Microm ${ }^{\mathrm{TM}} \mathrm{HM} 340 \mathrm{E}$ ). Every $30 \mu \mathrm{m}$, an image of the original block surface was taken (camera: Nikon D7200 ${ }^{\circledR}$; macro lens: Nikon AF-S VR Micro-Nikkor ${ }^{\circledR} 105$ mm 1:2,8G IF-ED; Nikon Corporation). Then, the surface was stained with a sodium sulfide solution (7\%) and a second picture was taken. Images were digitally processed in IrfanView ${ }^{\circledR}$ (version 4.41; Irfan Skiljan, http:// www.irfanview.com; conversion NEF to TIF) and Fiji (subtraction of corresponding unstained and stained images, and adjustment of brightness and contrast). One fiducial point per corner was used to align the stack of digital images in Amira ${ }^{\circledR}$. The obtained volume was converted to 8-bit grayscale in Fiji. In defined distance intervals, sections of the specimen were mounted on glass slides, stained using a modified Azan staining protocol, and digitized as above. The digitized sections were rigidly aligned in Amira ${ }^{\circledR}$. 


\section{MicroCT scanning}

A $\mu$ CT scan of the untreated adult Bufo bufo specimen (ZMH A04660) was performed using a YXLON FF35 CT (YXLON International GmbH). Subsequently, the specimen was contrast-stained with Lugol's solution (modified from Metscher 2009; concentration: 1\%, staining duration: 7 days, changed twice) and scanned in a YXLON FF20 CT. The unstained and stained scans were registered in Amira ${ }^{\circledR}$. The adult specimen of Rhinella marina (ZMH A15443) was contrast-stained with Lugol's solution (concentration: $1 \%$, staining duration: 8 days, changed twice) and $\mu \mathrm{CT}$ scanned in a Phoenix vltomelx L 450 (GE Sensing and Inspection Technologies $\mathrm{GmbH}$ ). All $\mu \mathrm{CT}$ scans were performed in an ethanol-saturated atmosphere. The volumes were reconstructed from X-ray projections using the software delivered with the respective scanner.

\section{Segmentation, $3 \mathrm{~d}$ reconstruction, and visualization}

All volumes were imported into Amira ${ }^{\circledR}$ and the shoulder joint muscles and contextual skeletal elements (in larvae: only chondrified or ossified parts, no condensations of mesenchymal cells or perichondrium/periosteum) of the right side were digitally dissected (i.e., segmented; Segmentation Editor with Brush tool). Bone and cartilage were not distinguished in most specimens. The left instead of the right side was segmented in Bombina orientalis ZMH A12427, Bufo bufo ZMH A04660, and Rhinella marina ZMH A15443 due to tissue visibility/damage on the right side. Bombina orientalis ZMH A12427 was mirrored to obtain consistent illustrations. In addition, nerves innervating the shoulder joint muscles were also segmented in the Stage 41 and 42 larvae and in the adult specimen of Alytes obstetricans. The original aligned digitized histological sections were used for comparison if possible and necessary. Polygon surfaces of the segmented anatomical elements were created and simplified by iterative reduction of polygon count and smoothing in Amira ${ }^{\circledR}$ and the surfaces were exported in obj format; surface generation and export were accelerated using a custom macro (MultiExport; see Engelkes et al. (2018) for details).

The simplified polymesh surfaces of the $R$. marina larvae and A. obstetricans were imported into MODO ${ }^{\circledR}$ (version $10.1 \mathrm{v} 2$; The Foundry) and manually edited (filling of holes, correction of artifacts, smoothing). The surfaces of some nerves showed considerable artifacts (i.e., discontinuity or holes) and needed major manual editing; care was taken to maintain the important properties (i.e., relative position to other anatomical elements and connections to muscles), but the form and thickness may not represent the actual conditions. The surfaces produced from A. obstetricans (ZMH A12442) were used to generate a schematic, generalized anuran model of all muscle portions and respective nerves observed across species by manually modifying the surfaces of the anatomical structures present and adding elements not present in that specimen. All surfaces were given descriptive colors (bone: beige; cartilage: blue; skeletal elements without distinguishing bone and cartilage: gray; muscles: various shades of red, such that adjacent muscles had different colors; nerves: yellow) prior to image rendering.

The muscle configurations in the adult specimens of $B$. bufo (ZMH A04660) and $R$. marina (ZMH A15443) were illustrated by combining polygon surfaces (skeleton) and volume renders (muscles) in Amira ${ }^{\circledR}$; this approach allowed for the visualization of the fiber orientation in some muscles. Final figures were arranged and labeled in Adobe ${ }^{\circledR}$ Illustrator ${ }^{\circledR}$ CS6 (version 16.0.3; Adobe ${ }^{\circledR}$ Systems Software).

\section{Muscle homology and nomenclature}

We define shoulder joint muscles pragmatically as the set of all muscles that cross the shoulder joint from their respective origin to their point of insertion. Hypotheses on the interspecific homology (in terms of primary homology; de Pinna 1991) of muscle units were derived by following the criteria for homology introduced by Remane (1952). Two or more muscle units were considered to be homologous if they showed a similar relation to other (homologous) anatomical structures (first criterion of Remane 1952) and could be connected by similar (intermediate) stages during the ontogenetic development (third criterion of Remane 1952; also see Kerr 1955). The first criterion was mainly applied for the relative locations of the muscle attachment sites and the position of the muscle units to one another. The innervation was also considered as it has been proven useful for the identification and homologization of muscles (e.g., Romer 1924; Holliday and Witmer 2007) and because the branching pattern of the major nerves supplying the forelimb muscles seems to be rather conserved across tetrapods (Hirasawa and Kuratani 2018); yet, it should be noted that some studies (e.g., Cunningham 1890; Romer 1922; Haines 1935; Minkoff 1974) questioned the value of nerve supply for determining muscle homologies. Considering these previous reports on the usefulness of nerves for the determination of muscle homologies, we believed that the position of muscle units relative to major nerves is a reliable criterion to identify homologous muscle units if a common branching pattern was observed across species. In contrast, we assumed that nerve supplies might be misleading if there was no common branching pattern or if there were differences regarding minor nerves.

We suggest a nomenclature for the observed shoulder joint muscles and justify the selection of muscle names in the discussion section. To avoid confusing the reader with previous muscle terms, for consistency, we already apply those muscle names in the results section that we eventually 
suggest on the basis of the evidence presented in this work. In general, the muscle names established by Gaupp (1896), Bigalke (1927), or Ritland (1955) were kept if they were consistently applied in the literature and seemed appropriate to reflect the ontogenetic, and thereby possibly also the evolutionary development. Table 2 provides nomenclatural comparison with the mentioned references. Nerve terminology follows Gaupp (1899).

\section{Results}

In the Bombina, Rana, and Rhinella specimens examined (Table 1), the skeleton of the pectoral girdle and forelimbs and the muscles of the shoulder joint developed in parallel and accomplished most of their development while the limb was still inside the branchial cavity. Although there were species-specific differences in the timing of the developmental events, the general pattern of skeletogenesis was as follows: The skeletal elements (except for the dermal bones) arose from various centers of chondrification in pre-cartilaginous condensations of mesenchymal cells. The cartilaginous anlagen grew and, where appropriate, fused with one another to form a cartilaginous skeletal precursor element. Eventually, the cartilaginous precursors ossified.

Combining the observations of all larval and adult specimens, we discerned 18 distinct muscle units crossing the shoulder joint (Table 3). Some of these units, however, were species-specifically fused or did not separate during ontogeny. The following general pattern of myogenesis was found in the ontogenetic series examined: The shoulder joint muscles differentiated from condensations of pre-muscle cells. In the earliest developmental stages, Stages 32-33, the anlage of the $\mathrm{m}$. anconaeus and three pre-muscle masses were present; one of the pre-muscle masses was located dorsal, the other two ventral to the humerus. In subsequent stages, the condensations of the pre-muscle cells split into smaller units that differentiated into the distinct shoulder joint muscles. The pre-muscle mass located dorsal to the humerus differentiated into the mm. dorsalis scapulae, latissimus dorsi, scapulohumeralis superficialis, scapulohumeralis profundus anterior, and scapulohumeralis profundus posterior. The anterior mass of the two pre-muscle masses located ventral to the humerus split into the $\mathrm{mm}$. cleidohumeralis, episternohumeralis, coracoradialis, and supracoracoideus, whereas the posteroventral pre-muscle mass differentiated into the $\mathrm{mm}$. pectoralis, coracobrachialis, and subcoracoscapularis; this posteroventral pre-muscle mass also gave rise to the $\mathrm{m}$. cutaneus pectoris in Rana temporaria. The two pre-muscle masses ventral to the developing humerus were barely separable in the earliest developmental stage of $R$. temporaria (ZMH A14736). Nerves were present and in contact with the pre-muscle masses or muscle units in all stages examined, even the earliest ones.

\section{Species-specific muscle variations}

Eighteen distinct muscle units crossing the shoulder joint were observed in the species examined (Figs. 1-3, Table 3), but not all these units were present in all specimens. The muscles and their respective origins and insertions are described in Table 3; in the following, only interspecific differences are reported.

In Ascaphus truei, the mm. scapulohumeralis superficialis, cleidohumeralis, and episternohumeralis formed one continuous muscle complex. The anteromedial part of the $\mathrm{m}$. supracoracoideus was continuous with this muscle complex, but distinct from it at the insertion. A large part of the $\mathrm{m}$. supracoracoideus was covered by the anteriorly expanded portio sternalis of the $\mathrm{m}$. pectoralis. The $\mathrm{m}$. coracobrachialis was split into a pars dorsalis and a pars ventralis; the pars dorsalis was continuous with the portio coracoidea of the $\mathrm{m}$. pectoralis. The $\mathrm{m}$. coracobrachialis and the portio coracoidea of the $\mathrm{m}$. pectoralis were continuous at their insertions in Alytes obstetricans; the insertions of these two muscles were adjacent in the latest larval stage considered (Stage 41) of Bombina orientalis.

Rhinella marina and Bufo bufo were very similar with respect to the configuration of their shoulder joint muscles (Electronic Supplementary Material Figs S1-S3). The major difference between these species concerned the $\mathrm{m}$. episternohumeralis: in $R$. marina, this muscle was continuous with the $\mathrm{m}$. supracoracoideus at its origin and along most of its length (muscles artificially separated for illustrational purpose), whereas in $B$. bufo, these muscles were clearly separated at their origins and along most of their lengths. In $B$. bufo, there was a tendency toward the formation of a pars ventralis and a pars dorsalis within the $\mathrm{m}$. coracobrachialis, but these parts were mostly continuous and may not be considered to be distinct muscle units. In both species, the m. supracoracoideus was present with an anterior and a posterior muscle unit; these two parts together claimed approximately the same space on the ventral part of the girdle as the undivided $\mathrm{m}$. supracoracoideus in the other species.

In the latest developmental stage of Rana temporaria considered herein (Stage 41), the m. scapulohumeralis superficialis originated from the medial surface of the pars glenoidalis of the scapula, the adjacent cartilage, and the lateral part of the coracoid; the origin of this muscle was not continuous with the origin of the $\mathrm{m}$. scapulohumeralis profundus anterior. The $\mathrm{mm}$. cleidohumeralis and coracobrachialis were each present with two parts that were continuous at their insertions. In addition, the pars superficialis of the $\mathrm{m}$. cleidohumeralis was barely separable form the $\mathrm{m}$. scapulohumeralis superficialis at 
its origin. Both parts of the m. coracobrachialis together claimed about the same space as the undivided $\mathrm{m}$. coracobrachialis in the other species. The $\mathrm{m}$. subcoracoscapularis was closely associated and mostly continuous with the pars dorsalis of the $\mathrm{m}$. coracobrachialis; the former inserted more proximal on the humerus than observed in the other species. A m. cutaneus pectoris was present and originated from the ventral surface of $\mathrm{m}$. rectus abdominis and inserted onto the skin.

\section{Species-specific innervation of the shoulder joint muscles}

The shoulder joint muscles were innervated by various branches of the plexus brachialis that was formed by fibers of the nn. spinalis II-IV (Fig. 4). The rr. dorsalis scapulae anterior and posterior arose from about the lateral aspect of the plexus brachialis. The $r$. dorsalis scapulae anterior innervated the $\mathrm{m}$. dorsalis scapulae and the group of scapulohumeralis muscles. It either passed through the m. scapulohumeralis profundus anterior before it ended in the $\mathrm{m}$. scapulohumeralis superficialis (Alytes obstetricans, Rana temporaria; Fig. 1c) or entered between these two muscles (Ascaphus truei, Bombina orientalis, Rhinella marina; Fig. 5a, b). The r. dorsalis scapulae posterior innervated the posterior part of the $\mathrm{m}$. dorsalis scapulae and the $\mathrm{m}$. latissimus dorsi.

The r. coraco-clavicularis arose from the anterior aspect of the plexus brachialis, passed through the opening between the procoracoid and coracoid, and innervated the $\mathrm{mm}$. coracoradialis, supracoracoideus (only anterior part or portion), episternohumeralis, and cleidohumeralis (both portions if two were present). In all species examined, the ramus innervating the $\mathrm{m}$. coracoradialis was the first to separate from the r. coraco-clavicularis. In Ascaphus truei, B. orientalis, and Alytes obstetricans, there was a separate branch arising from the r. coraco-clavicularis that formed an anastomosis with the r. coraco-brachialis of the r. pectoralis communis of the $\mathrm{n}$. brachialis longus inferior; the anastomosis and the respective rami were located dorsal (profound) to the $\mathrm{mm}$. coracoradialis, supracoracoideus, and the portions of the $\mathrm{m}$. pectoralis, whereas they (anastomosis and rami) laid ventral (superficial) to the m. coracobrachialis (Fig. 2). No

Table 2 Hypotheses on shoulder joint muscle homologies across selected species and implied synonyms of muscle names among different authors

\begin{tabular}{|c|c|c|c|c|}
\hline \multicolumn{2}{|l|}{ Suggested name } & $\begin{array}{l}\text { Ascaphus truei } \\
\text { (Ritland 1955) }\end{array}$ & $\begin{array}{l}\text { Rana } \\
\text { (Gaupp 1896) }\end{array}$ & $\begin{array}{l}\text { Bufo bufo } \\
\text { (Bigalke 1927) }\end{array}$ \\
\hline \multicolumn{2}{|l|}{ m. coracoradialis [cr] } & m. coraco-radialis & m. coraco-radialis & $\mathrm{m}$. coraco-radialis \\
\hline \multirow{2}{*}{$\begin{array}{l}\text { m. supracoracoideus } \\
\text { [sup] }\end{array}$} & $\begin{array}{l}\text { portio anterior } \\
\text { [supa] }\end{array}$ & \multirow{2}{*}{ m. supracoracoideus superficialis } & \multirow{2}{*}{ m. pectoralis portio epicoracoidea } & m. pectoralis portio epicoracoidea \\
\hline & $\begin{array}{l}\text { portio posterior } \\
\text { [supp] }\end{array}$ & & & $\begin{array}{l}\text { m. coracobrachialis brevis pars } \\
\text { superficialis }\end{array}$ \\
\hline \multicolumn{2}{|c|}{ m. coracobrachialis pars ventralis [cbv] } & m. supracoracoideus profundus & $\begin{array}{l}\text { m. coraco-brachialis brevis pars } \\
\text { superficialis }\end{array}$ & \multirow{3}{*}{ m. coraco-brachialis brevis pars profunda } \\
\hline \multicolumn{2}{|c|}{ m. subcoracoscapularis [sub] $\ldots . . . .}$. & m. subcoracoscapularis & \multirow{2}{*}{ m. coraco-brachialis brevis pars profunda } & \\
\hline \multirow{2}{*}{\multicolumn{2}{|c|}{$\begin{array}{l}\mathrm{m} . \text { coracobrachialis pars dorsalis [cbd] } \\
\mathrm{m} . \text { pectoralis portio coracoidea }[\mathrm{pc}]\end{array}$}} & \multirow{2}{*}{ m. coracobrachialis } & & \\
\hline & & & m. coraco-brachialis longus & m. coraco-brachialis longus \\
\hline \multicolumn{2}{|c|}{ m. pectoralis portio sternalis [ps] } & m. pectoralis caput sternalis & m. pectoralis portio sternalis & m. pectoralis portio sternalis \\
\hline \multicolumn{2}{|c|}{ m. pectoralis portio abdominalis [pa] } & m. pectoralis caput abdominalis & m. pectoralis portio abdominalis & m. pectoralis portio abdominalis \\
\hline \multicolumn{2}{|c|}{$\begin{array}{l}\text { m. scapulohumeralis profundus posterior } \\
\text { [shpp] }\end{array}$} & m. scapulohumeralis profundus posterior & [not described] & m. scapulo-humeralis profundus posterior \\
\hline \multicolumn{2}{|c|}{$\begin{array}{l}\text { m. scapulohumeralis profundus anterior } \\
\text { [shpa] }\end{array}$} & m. scapulohumeralis profundus anterior & \multirow{3}{*}{ m. deltoideus pars scapularis } & $\mathrm{m}$. scapulo-humeralis profundus anterior \\
\hline \multicolumn{2}{|c|}{ m. scapulohumeralis superficialis [shs] } & m. deltoideus [d2, cleidohumeralis] & & m. deltoideus pars scapularis \\
\hline \multirow{2}{*}{$\begin{array}{l}\text { m. cleidohumeralis } \\
\text { [clh] }\end{array}$} & $\begin{array}{l}\text { pars superficialis } \\
\text { [clhs] }\end{array}$ & $\mathrm{m}$. deltoideus & & \multirow{2}{*}{ m. deltoideus pars clavicularis } \\
\hline & $\begin{array}{l}\text { pars profunda } \\
{[\mathrm{clhp}]}\end{array}$ & [d3, cleidohumeralis] & m. deltoideus pars clavicularis & \\
\hline \multicolumn{2}{|c|}{ m. episternohumeralis [eh] } & $\mathrm{m}$. deltoideus [d1, episternohumeralis] & $\mathrm{m}$. deltoideus pars episternalis & $\begin{array}{l}\text { m. deltoideus pars cleido-humeralis } \\
\text { longus }\end{array}$ \\
\hline \multicolumn{2}{|c|}{ m. dorsalis scapulae [ds] } & $\mathrm{m}$. dorsalis scapulae & m. dorsalis scapulae & m. dorsalis scapulae \\
\hline \multicolumn{2}{|c|}{ m. latissimus dorsi [1d] } & m. latissimus dorsi & m. latissimus dorsi & m. latissimus dorsi \\
\hline \multicolumn{2}{|c|}{ m. anconaeus caput scapulare [ancs] } & $\mathrm{m}$. anconaeus caput scapulare & $\mathrm{m}$. anconaeus caput scapulare & m. anconaeuscaput scapulare \\
\hline \multicolumn{2}{|c|}{ m. cutaneus pectoris $[\mathrm{cp}]$} & - & m. cutaneus pectoris ${ }^{\mathrm{a}}$ & - \\
\hline
\end{tabular}

Dotted line: muscles not entirely separated (e.g., continuous at origin)

a The $\mathrm{m}$. cutaneous pectoris was present in Rana temporaria only and was ontogenetically derived from the portionis sternalis and abdominalis of the $\mathrm{m}$. pectoralis; the $\mathrm{m}$. cutaneous pectoris, therefore, might as well have been included in the homologization of the two pectoralis portions 


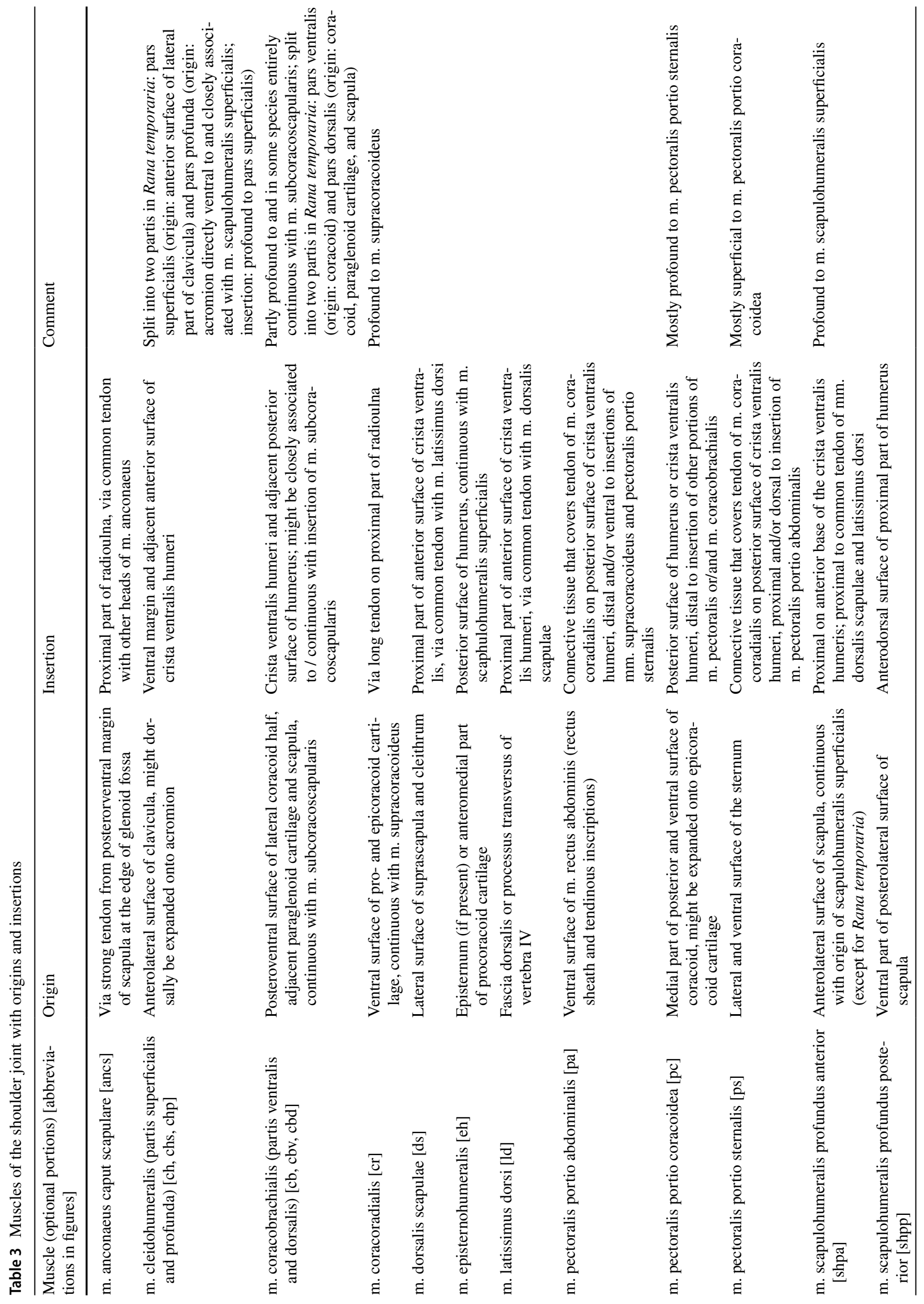


such anastomosis was present in R. marina (Fig. 6) or Rana temporaria.

The $\mathrm{n}$. brachialis longus inferior separated from the posterior aspect of the plexus brachialis and gave rise to, among others, the r. pectoralis communis, which in turn split into the rr. coraco-brachialis and pectoralis proprius. The r. pectoralis communis and its derivatives laid profound to the caput scapulare of the m. anconaeus. In Ascaphus truei, $B$. orientalis, and Alytes obstetricans, the r. pectoralis communis passed between the $\mathrm{mm}$. subcoracoscapularis and coracobrachialis (Fig. 3a, b), whereas the rr. coraco-brachialis and pectoralis proprius separated before they entered the space between the $\mathrm{mm}$. subcoracoscapularis and coracobrachialis in Rhinella marina and Rana temporaria (Fig. 5d, e). In the latter two species, only the r. coraco-brachialis passed between the two muscles, the $r$. pectoralis proprius laid superficial to them. In all species examined, the $r$. coraco-brachialis innervated the $\mathrm{mm}$. subcoracoscapularis, coracobrachialis, and the posterior part or portion of the $\mathrm{m}$. supracoracoideus. In A. obstetricans (Fig. 4a, b) and R. temporaria, the r. coraco-brachialis also innervated the portio coracoidea of the $\mathrm{m}$. pectoralis, whereas this portion was innervated by the $\mathrm{r}$. pectoralis proprius in $B$. orientalis and Rhinella marina (Figs. 4d, f, 5d, e). No distinct portio coracoidea was observed in Ascaphus truei, but the muscle fibers most likely representing the portio coracoidea (as inferred from the relative position to the rr. coraco-brachialis and pectoralis proprius) received nerve supply from both, the rr. coraco-brachialis and pectoralis proprius. The $\mathrm{r}$. pectoralis proprius of the $r$. pectoralis communis innervated the portionis sternalis and abdominalis of the $\mathrm{m}$. pectoralis in all species examined and, as described above, in B. orientalis, R. marina, and A. truei also the portio coracoidea. In Rana temporaria, the r. pectoralis proprius also supplied the $\mathrm{m}$. cutaneus pectoris.

The $\mathrm{n}$. brachialis longus superior separated from the posterior aspect of the plexus brachialis in close proximity to the $\mathrm{n}$. brachialis longus inferior. It innervated, among others, the heads of the $\mathrm{m}$. anconaeus with one exception: in Rhinella marina, the caput scapulare received nerve supply from two rami that arose from the plexus brachialis in close proximity to the base of the $\mathrm{n}$. brachialis longus superior.

\section{Development of the skeleton}

Precursors of the pectoral girdle skeleton and long bones of the forelimbs were present and developed throughout all larval stages considered herein. Despite species-specific differences, the following general pattern was observed: in the earliest of the considered stages, the pectoral girdle skeleton was present by cartilaginous precursors of the elements (scapula and coracoid) that form the glenoid fossa 

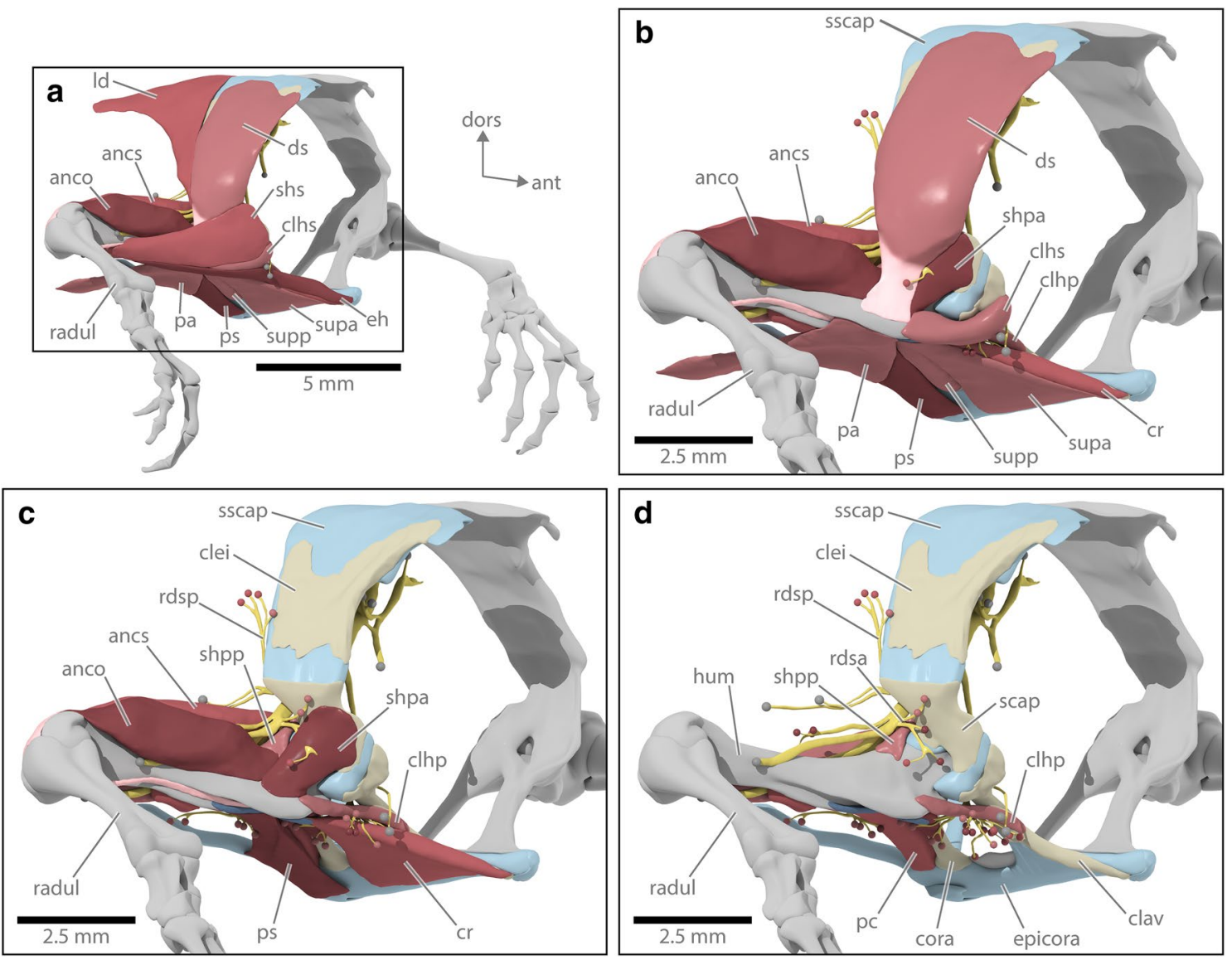

Fig. 1 Hypothetical generalized pattern of shoulder joint muscles with respective nerve supplies in anurans. a-d Anterolateral views, muscle layers successively removed. Surface model originally derived from a 3d representation of Alytes obstetricans (ZMH A12442) to serve as a model, but manually modified (mm. cleidohumeralis and supracoracoideus split into two portions each, nerve supplies adjusted) and no longer representing the character states of that species. Spheres: nerve ending in muscle (red spheres) or cut (gray, no connection to shoulder joint muscles). Red: muscles (different shades for better visual separation of adjacent muscles); yellow: nerves; beige: bone; light blue: cartilage; dark blue: connective tissue; light gray: skeletal element with no distinction of bone and cartilage. anco: heads of $\mathrm{m}$. anconaeus not crossing the shoulder joint; ancs: $\mathrm{m}$. anco-

naeus caput scapulare; ant: anterior; clav: clavicula; clei: cleithrum; clhp: $\mathrm{m}$. cleidohumeralis pars profunda; clhs: $\mathrm{m}$. cleidohumeralis pars superficialis; cora: coracoid; cr: m. coracoradialis; dors: dorsal; ds: $\mathrm{m}$. dorsalis scapulae; eh: m. episternohumeralis; epicora: epicoracoid cartilage; hum: humerus; ld: m. latissimus dorsi; pa: m. pectoralis portio abdominalis; $\mathrm{pc}$ : $\mathrm{m}$. pectoralis portio coracoidea; $\mathrm{ps}$ : $\mathrm{m}$. pectoralis portio sternalis; radul: radioulna; rdsa: $r$. dorsalis scapulae anterior; rdsp: r. dorsalis scapulae posterior; scap: scapula; shs: $\mathrm{m}$. scapulohumeralis superficialis; shpa: m. scapulohumeralis profundus anterior; shpp: m. scapulohumeralis profundus posterior; sscap: suprascapula; supa: $\mathrm{m}$. supracoracoideus portio anterior; supp: $\mathrm{m}$. supracoracoideus portio posterior

and, case-specifically, by the ventral parts of the suprascapula or condensations of cells preceding the suprascapula. There case-specifically also was a separate precursor of the procoracoid cartilage. During the course of development, the coracoid and procoracoid extended ventrally and, in later stages, grew toward one another (formation of epicoracoid) with cartilaginous tissue.

With about the onset of metamorphic climax, the orientation of the skeletal complex formed by the coracoid, procoracoid, and epicoracoid stated to shift from a more vertical toward a rather horizontal orientation. In addition, these ventral elements grew toward their counterparts of the other girdle half. The scapula and suprascapula extended dorsally. Humerus, radius, and ulna lengthened throughout all developmental stages and approached their adult form (i.e., development of crests, fusion of radius and ulna). The ossification of the endochondral bones, as well as the development of the dermal bones (clavicula and cleithrum), began in bone- and species-specific stages. More detailed descriptions of the chondrogenesis and ossification during larval development and metamorphosis have been published elsewhere (e.g., Púgener and Maglia 1997; Maglia and Púgener 1998; Baleeva 2001, 2009; Shearman 2005, 2008; Havelková and Roček 2006) and are beyond the scope of this study. 


\section{Development of the shoulder joint muscles in Rhinella marina}

In the earliest larval stage of Rhinella marina considered herein (Stage 32-33; ZMH A14928; Fig. 7a, b), the muscles dorsal to the shoulder joint were present by a distinct caput scapulare of the $\mathrm{m}$. anconaeus (distally continuous with other heads of $\mathrm{m}$. anconaeus), a common precursor of the $\mathrm{mm}$. dorsalis scapulae and latissimus dorsi, one pre-muscle mass representing the $\mathrm{mm}$. scapulohumeralis profundus anterior and superficialis, as well as a distinct mass representing the $\mathrm{m}$. scapulohumeralis profundus posterior. Both precursors of the scapulohumeralis muscles were connected by a loose accumulation of undifferentiated cells. Ventrally, one pre-muscle mass preceded the $\mathrm{mm}$. supracoracoideus (portionis anterior and posterior), episternohumeralis, and cleidohumeralis. This mass was located superficial to and was medioventrally continuous with the precursor of $\mathrm{m}$. coracoradialis. Posteroventrally, the $\mathrm{mm}$. subcoracoscapularis, coracobrachialis, and all portions of $\mathrm{m}$. pectoralis were present by one common pre-muscle mass; the cells representing the future $\mathrm{m}$. pectoralis seemed less differentiated than the cells preceding the other muscles, so the m. pectoralis could artificially be separated from the others.

In Stage 34 (ZMH A14930; Fig. 7c, d), the undifferentiated cells connecting the $\mathrm{m}$. scapulohumeralis profundus posterior to the $\mathrm{mm}$. scapulohumeralis profundus anterior and superficialis disappeared and the $\mathrm{m}$. latissimus dorsi became distinguishable from the $\mathrm{m}$. dorsalis scapulae. Anteroventrally, the $\mathrm{m}$. cleidohumeralis as well as the portio

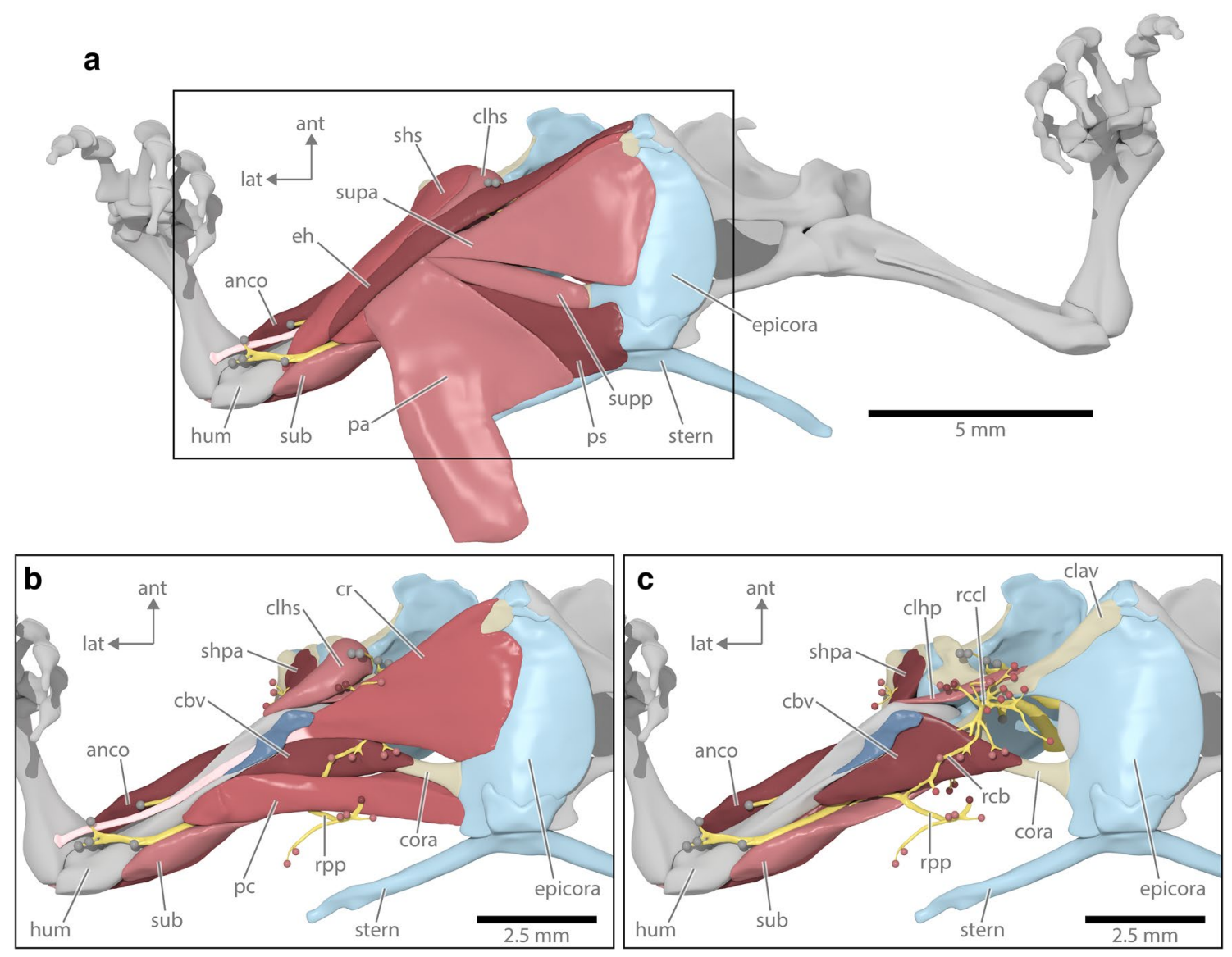

Fig. 2 Hypothetical generalized pattern of shoulder joint muscles with respective nerve supplies in anurans. a-c Ventral views, muscle layers successively removed. Same surface model as in Fig. 1. Spheres: nerve ending in muscle (red spheres) or cut (gray, no connection to shoulder joint muscles). Red: muscles (different shades for better visual separation of adjacent muscles); yellow: nerves; beige: bone; light blue: cartilage; dark blue: connective tissue; light gray: skeletal element with no distinction of bone and cartilage. anco: heads of $\mathrm{m}$. anconaeus not crossing the shoulder joint; ant: anterior; cbv: $\mathrm{m}$. coracobrachialis pars ventralis; clav: clavicula; clhp: $\mathrm{m}$. cleidohumeralis pars profunda; clhs: m. cleidohumeralis pars superficialis; cora: coracoid; cr: m. coracoradialis; eh: m. episternohumeralis; epicora: epicoracoid cartilage; hum: humerus; lat: lateral; pa: m. pectoralis portio abdominalis; $\mathrm{pc}$ : $\mathrm{m}$. pectoralis portio coracoidea; $\mathrm{ps}$ : $\mathrm{m}$. pectoralis portio sternalis; rcb: r. coraco-brachialis; rccl: r. coracoclavicularis; rpp: r. pectoralis proprius; shs: m. scapulohumeralis superficialis; shpa: m. scapulohumeralis profundus anterior; stern: sternum; sub: m. subcoracoscapularis; supa: m. supracoracoideus portio anterior; supp: $\mathrm{m}$. supracoracoideus portio posterior 
posterior of the $\mathrm{m}$. supracoracoideus split from the remaining pre-muscle mass representing the future portio anterior of the $\mathrm{m}$. supracoracoideus and the $\mathrm{m}$. episternohumeralis; the separations were most obvious at the origins, whereas the muscles were almost continuous at their insertions. The posteroventral muscle precursor split into several (pre-)muscle masses: The m. pectoralis portio abdominalis became entirely distinct, while the portionis sternalis and coracoidea were separated at their insertions (the insertion of the portio coracoidea shifted to a more distal position), but remained continuous at the origin. The mm. coracobrachialis and subcoracoscapularis formed one separate muscle mass.

The specimens of Stages 37 (ZMH A14933; Fig. 7e-h) and 41 (ZMH A14937; Figs. 5, 6) showed all muscle units also present in the adult specimen (ZMH A15443; Electronic Supplementary Material Figs S1-S3): The mm. scapulohumeralis superficialis and profundus anterior were continuous at their origins, but clearly separated at their insertions. The same was observed for the $\mathrm{m}$. episternohumeralis and the portio anterior of the supracoracoideus, as well as for $\mathrm{mm}$. coracobrachialis and subcoracoscapularis. At their origins, the muscles of these complexes could only artificially be separated in the adult specimen by tracing the muscles fibers from the insertion to the origin. The portionis sternalis and coracoidea of the m. pectoralis were entirely separated.

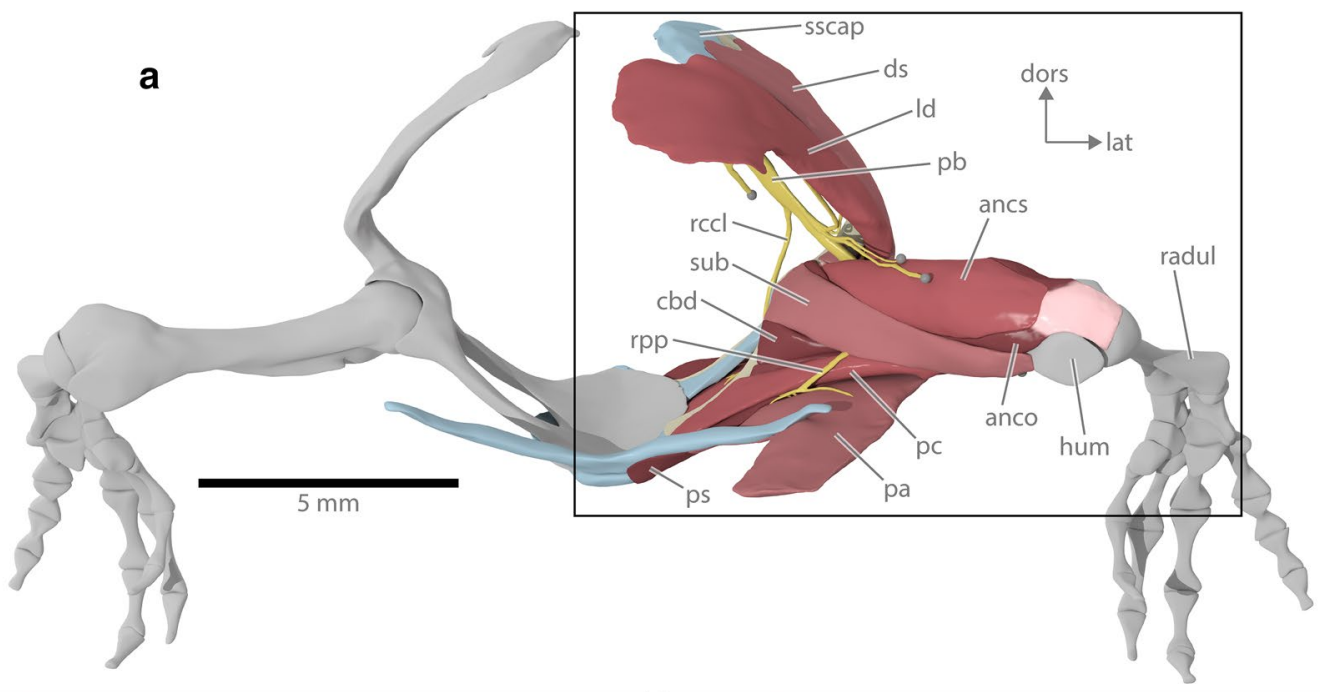

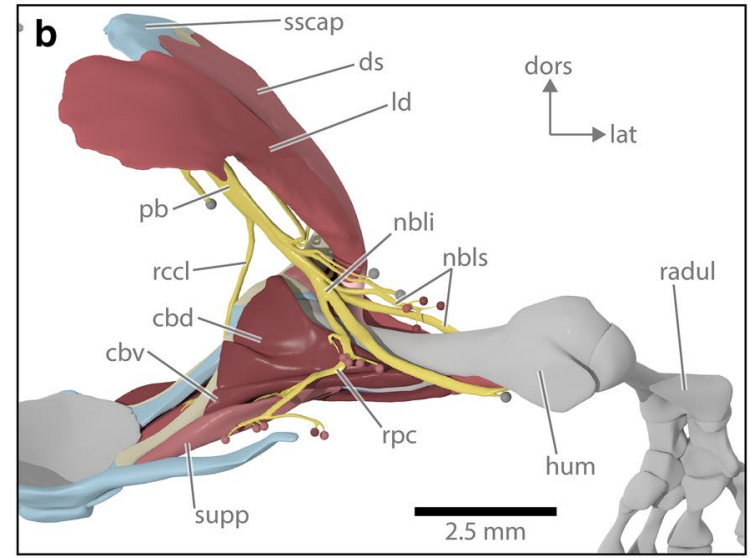

Fig. 3 Hypothetical generalized pattern of shoulder joint muscles with respective nerve supplies in anurans. a-c Posterior views, muscle layers successively removed. Same surface model as in Fig. 1. Spheres: nerve ending in muscle (red spheres) or cut (gray, no connection to shoulder joint muscles). Red: muscles (different shades for better visual separation of adjacent muscles); yellow: nerves; beige: bone; light blue: cartilage; dark blue: connective tissue; light gray: skeletal element with no distinction of bone and cartilage. anco: heads of $\mathrm{m}$. anconaeus not crossing the shoulder joint; ancs: $\mathrm{m}$. anco-

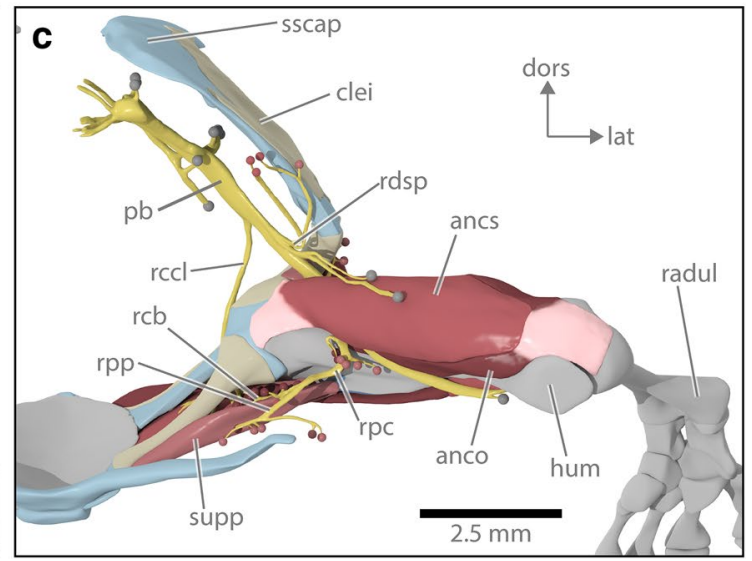

naeus caput scapulare; cbd: $\mathrm{m}$. coracobrachialis pars dorsalis; cbv: $\mathrm{m}$. coracobrachialis pars ventralis; dors: dorsal; ds: $\mathrm{m}$. dorsalis scapulae; hum: humerus; ld: m. latissimus dorsi; lat: lateral; nbls: n. brachialis longus superior; nbli: $\mathrm{n}$. brachialis longus inferior; pa: $\mathrm{m}$. pectoralis portio abdominalis; pb: plexus brachialis; pc: m. pectoralis portio coracoidea; ps: m. pectoralis portio sternalis; radul: radioulna; rcb: $r$. coraco-brachialis; rccl: r. coraco-clavicularis; rpc: r. pectoralis communis; rpp: r. pectoralis proprius; sub: m. subcoracoscapularis; supp: $\mathrm{m}$. supracoracoideus portio posterior 

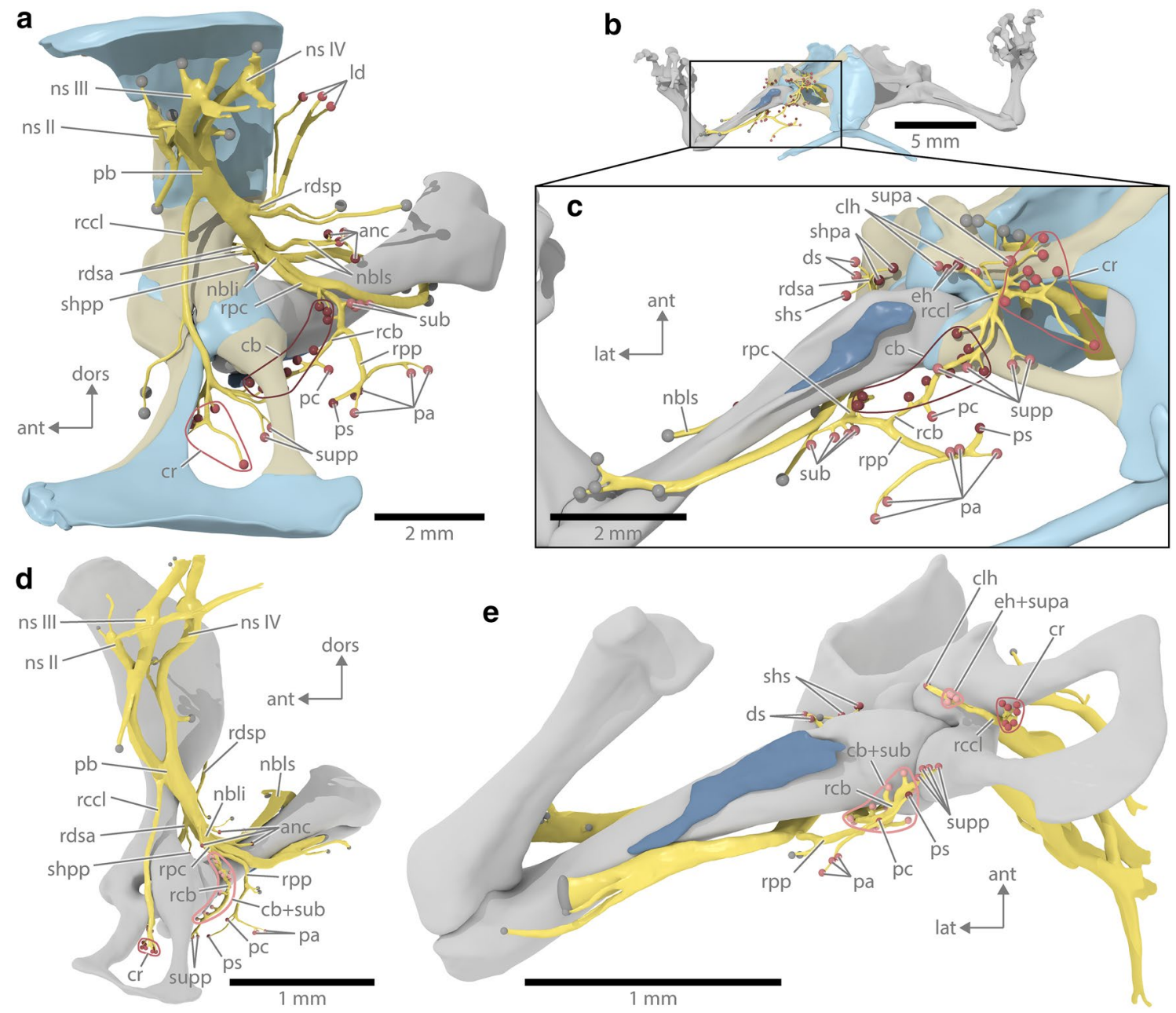

Fig. 4 Plexus brachialis and associated nerve branches innervating the shoulder joint muscles. Spheres: nerve ending in muscle (red spheres) or cut (gray, no connection to shoulder joint muscles). Yellow: nerves; beige: bone; light blue: cartilage; dark blue: connective tissue; light gray: skeletal element with no distinction of bone and cartilage. a-c Generalized pattern in anurans; same surface model as in Fig. 1. a Medial view of right pectoral girdle half and humerus. b Ventral view and $\mathbf{c}$ detail of ventral view of pectoral girdle and forelimbs. d-e Pattern of shoulder joint muscle innervation in a Rhinella marina larva (Stage 41, ZMH A14937). d Medial view of right pectoral girdle half and humerus, anterior to the left. e Ventral view of right pectoral girdle half and humerus, anterior to the top. anc: $\mathrm{m}$. anconaeus; ant: anterior, cb: m. coracobrachialis; clh: m. cleido- humeralis; cr: m. coracoradialis; dors: dorsal; ds: m. dorsalis scapulae; eh: m. episternohumeralis; lat: lateral; ld: m. latissimus dorsi; nbli: $\mathrm{n}$. brachialis longus inferior; nbls: $\mathrm{n}$. brachialis longus superior; ns: $n$. spinalis; pa: $m$. pectoralis portio abdominalis; pb: plexus brachialis; pc: m. pectoralis portio coracoidea; ps: m. pectoralis portio sternalis; rccl: r. coraco-clavicularis; rcb: r. coraco-brachialis; rdsa: r. dorsalis scapulae anterior; rdsp: r. dorsalis scapulae posterior; rpc: r. pectoralis communis; rpp: r. pectoralis proprius; shs: m. scapulohumeralis superficialis; shpa: m. scapulohumeralis profundus anterior; shpp: $\mathrm{m}$. scapulohumeralis profundus posterior; sub: $\mathrm{m}$. subcoracoscapularis; supa: $\mathrm{m}$. supracoracoideus portio anterior; supp: $\mathrm{m}$. supracoracoideus portio posterior

\section{Development of the shoulder joint muscles in Bombina orientalis}

The overall pattern of the development of the shoulder joint muscles in Bombina orientalis was similar to the one observed in Rhinella marina, but there were some differences. Most strikingly, most developmental events occurred in earlier larval stages than in R. marina. Other than in $R$. marina (m. episternohumeralis continuous with $\mathrm{m}$. supracoracoideus in Stage 32-33), the mm. episternohumeralis and cleidohumeralis formed one independent pre-muscle mass in the earliest considered developmental stage of $B$. orientalis (Stage 32, ZMH A12427); two portions were recognizable within this pre-muscle mass based on the cell orientation (Fig. 8a). As in later developmental stages of R. marina, the $\mathrm{mm}$. scapulohumeralis superficialis and profundus anterior 


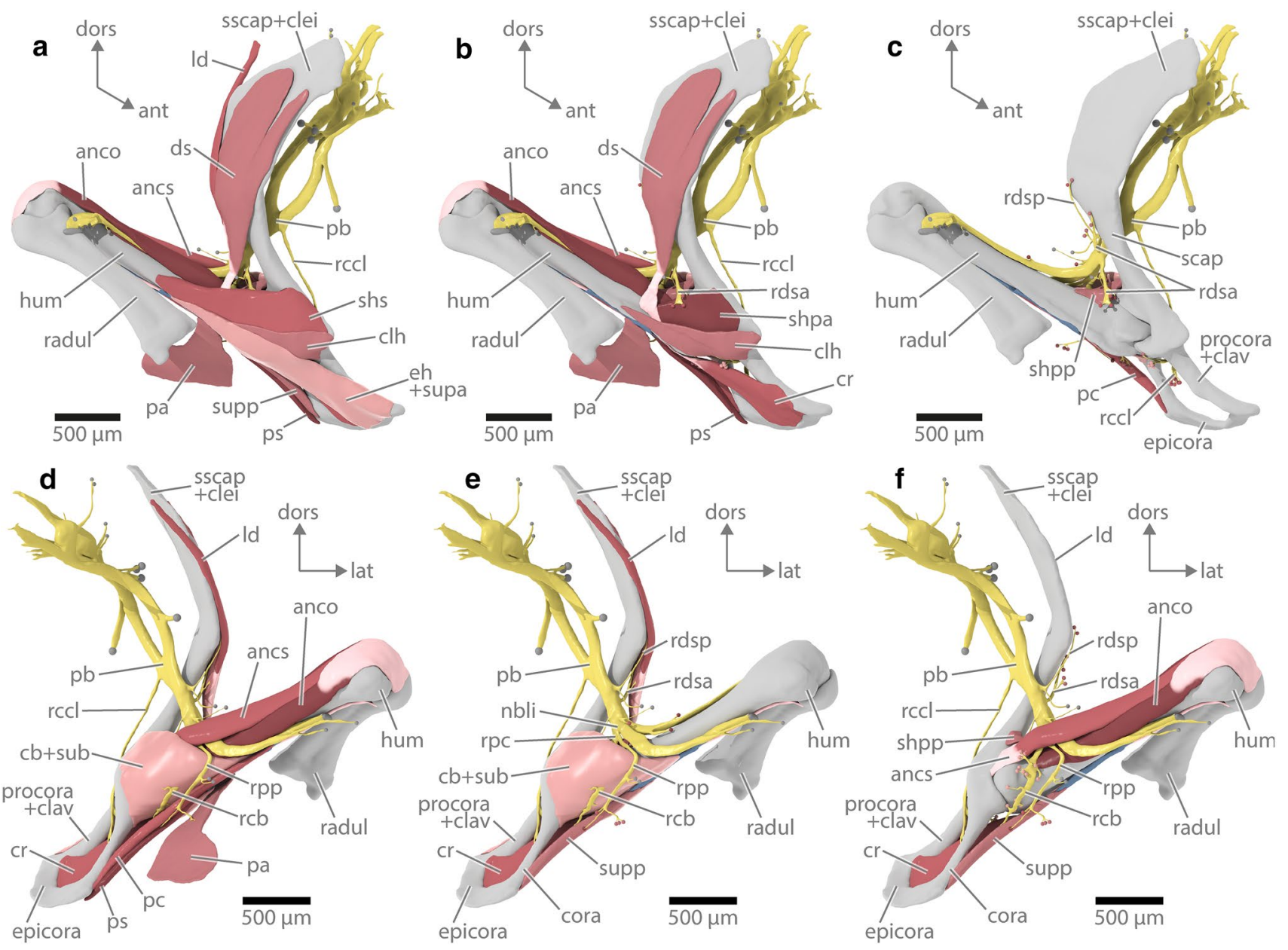

Fig. 5 Shoulder joint muscles with respective nerve supplies in Rhinella marian (Stage 41, ZMH A14937). Surfaces derived from aligned histological serial sections, muscle layers successively removed. Spheres: nerve ending in muscle (red spheres) or cut (gray, no connection to shoulder joint muscles). Red: muscles (different shades for better visual separation of adjacent muscles); yellow: nerves; dark blue: connective tissue; light gray: skeletal element with no distinction of bone and cartilage. a-c Anterolateral views of right pectoral girdle half. d-f Posterior views of right pectoral girdle half. anco: heads of $\mathrm{m}$. anconaeus not crossing the shoulder joint; ancs: $\mathrm{m}$. anconaeus caput scapulare; ant: anterior; cb: m. coracobrachialis; clav: clavicula; clei: cleithrum; clh: $\mathrm{m}$. cleidohumeralis; cr: $\mathrm{m}$. coracoradialis; dors: dorsal; ds: m. dorsalis scapulae; eh: m. epister-

in B. orientalis (ZMH A12427) were continuous at their origins, but clearly separated at their insertions (Fig. 8b). Both these muscles had no connection to the m. scapulohumeralis profundus posterior. The $\mathrm{mm}$. dorsalis scapulae and latissimus dorsi were distinct from each other as well. The caput scapulare of the $\mathrm{m}$. anconaeus was distinct at its origin and distally continuous with the other heads of the $\mathrm{m}$. anconaeus. Posteriorly, the precursors of the portionis abdominalis and sternalis of the $\mathrm{m}$. pectoralis were mostly continuous, but distinct at their insertions; the portio coracoidea was entirely separated from the former two portions. nohumeralis; epicora: epicoracoid cartilage; hum: humerus; lat: lateral; ld: m. latissimus dorsi; nbli: $\mathrm{n}$. brachialis longus inferior; pa: $\mathrm{m}$. pectoralis portio abdominalis; pb: plexus brachialis; $\mathrm{pc}$ : $\mathrm{m}$. pectoralis portio coracoidea; procora: procoracoid cartilage; ps: $\mathrm{m}$. pectoralis portio sternalis; radul: radioulna; rccl: r. coraco-clavicularis; rcb: $r$. coraco-brachialis; rdsa: r. dorsalis scapulae anterior; rdsp: r. dorsalis scapulae posterior; rpc: r. pectoralis communis; rpp: r. pectoralis proprius; scap: scapula; shs: $\mathrm{m}$. scapulohumeralis superficialis; shpa: $\mathrm{m}$. scapulohumeralis profundus anterior; shpp: $\mathrm{m}$. scapulohumeralis profundus posterior; sscap: suprascapula; sub: m. subcoracoscapularis; supa: m. supracoracoideus portio anterior; supp: m. supracoracoideus portio posterior

The mm. subcoracoscapularis and coracobrachialis were continuous at their origins and separated at the insertions (Fig. 8c).

In the $B$. orientalis specimen of Stage 35 (ZMH A12429), the $\mathrm{mm}$. episternohumeralis and cleidohumeralis remained mostly continuous at their insertions, but were clearly separated at the origins (Fig. 8d). Within the m. supracoracoideus, there was a tendency toward forming an anterior and a posterior portion (Fig. 8e), but the portions were closely associated and could not be considered distinct. The 
portionis abdominalis and sternalis of the $\mathrm{m}$. pectoralis were distinct from one another (Fig. 8f).

The muscle configuration in Stage 41 (ZMH A12435) resembled the one observed in Stage 35 with the exceptions that the $\mathrm{mm}$. episternohumeralis and cleidohumeralis, although laterally in close proximity to each other, were separated at their origins and insertions (Fig. $8 \mathrm{~g}-\mathrm{i}$ ). The $\mathrm{m}$. supracporacoideus formed one muscle mass with no tendency toward the formation of two portions.

\section{Development of the shoulder joint muscles in Rana temporaria}

The developmental pattern of the shoulder joint muscles in Rana temporaria was similar to the patterns observed in the other two species, but the condensations of pre-muscle cells were less differentiated in the earliest developmental stage considered herein (Stage 32-33, ZMH A14736). Dorsal to the humerus, the precursor of the $\mathrm{m}$. anconaeus was present as a condensation of pre-muscle cells, but the different heads of this muscle were inseparable. The mm. scapulohumeralis superficialis, profundus anterior and profundus posterior, dorsalis scapulae, and latissimus dorsi were present as a continuous pre-muscle mass (Fig. 9a-c); only the future common tendon of the $\mathrm{mm}$. dorsalis scapulae and latissimus dorsi was recognizable as a region of comparably densely packed cells (Fig. 9c). Ventral to the humerus, there were two pre-muscle masses that were mostly continuous and only separated by the already recognizable posterior part of the future m. coracoradialis (Fig. 9b); anteriorly, the m. coracoradialis formed one pre-muscle mass with the future mm. cleidohumeralis, episternohumeralis, and supracoracoideus (Fig. 9a). The pre-muscle mass posterior to the m. coracoradialis represented the future $\mathrm{mm}$. pectoralis, cutaneus pectoris, coracobrachialis, and subcoracoscapularis (Fig. 9b, c).

In the $R$. temporaria specimen of Stage 34 (ZMH A14739), the pre-muscle masses were somewhat more differentiated. Dorsally, the caput scapulare of the m. anconaeus was distinct at the origin and distally continuous with other heads of $\mathrm{m}$. anconaeus. The $\mathrm{mm}$. dorsalis scapulae and latissimus dorsi formed one pre-muscle mass that was clearly distinct from the group of scapulohumeralis muscles. The future mm. scapulohumeralis superficialis and profundus anterior were continuous (Fig. 9d, e), but separated from the $\mathrm{m}$. scapulohumeralis posterior. The anterior of the two ventral pre-muscle masses observed in Stage 32-33 (ZMH A14736) was clearly separable from the posterior one and the $\mathrm{m}$. coracoradialis became more distinct, but was still largely continuous with the common precursor of the future mm. cleidohumeralis, episternohumeralis, and supracoracoideus (Fig. 9e). Concerning the posteroventral
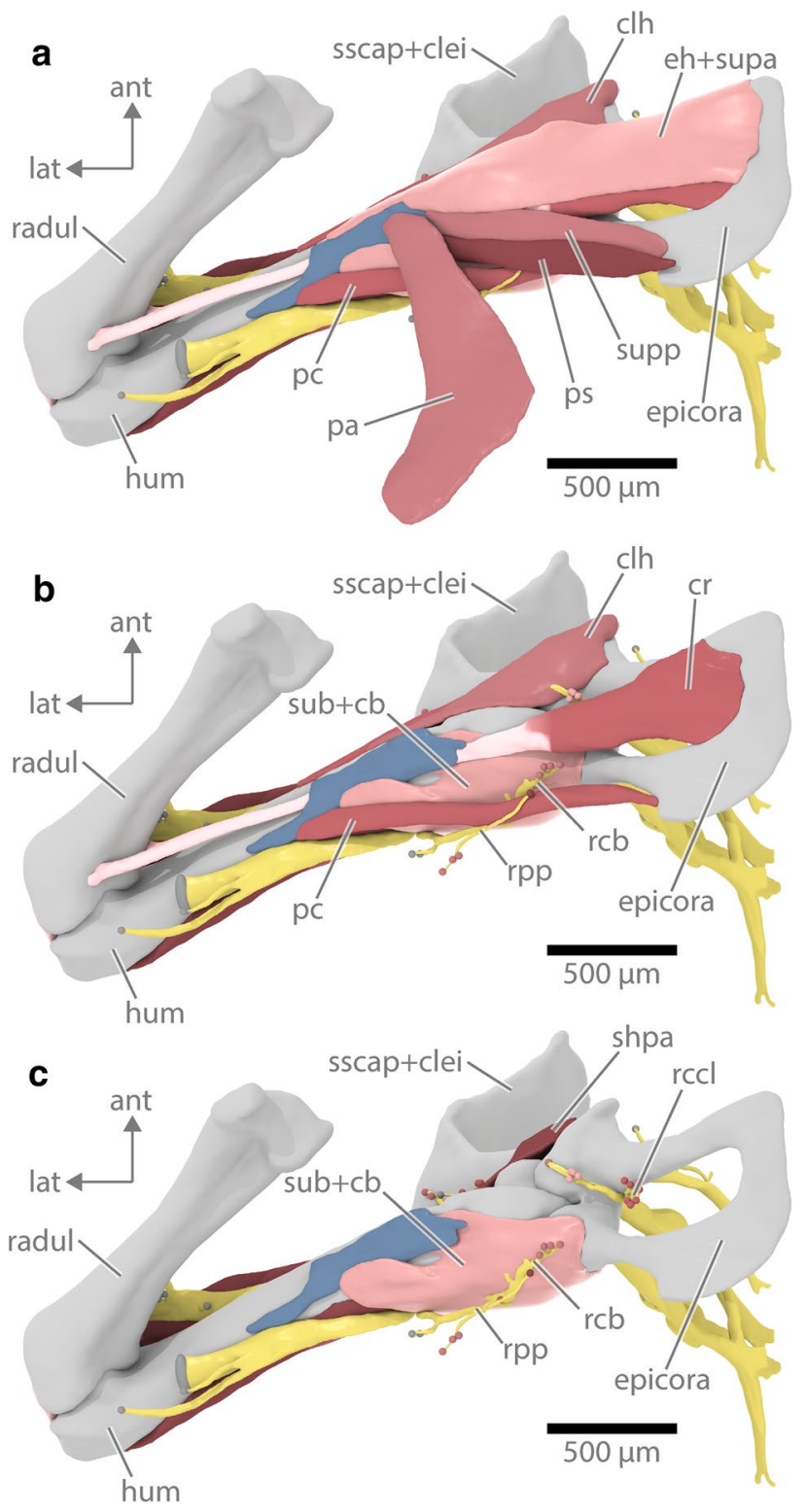

Fig. 6 Shoulder joint muscles with respective nerve supplies in Rhinella marina (Stage 41, ZMH A14937). Ventral views, muscle layers successively removed; mm. dorsalis scapulae and latissimus dorsi not shown. Surfaces derived from aligned histological serial sections. Spheres: nerve ending in muscle (red spheres) or cut (gray, no connection to shoulder joint muscles). Red: muscles (different shades for better visual separation of adjacent muscles); yellow: nerves; dark blue: connective tissue; light gray: skeletal element with no distinction of bone and cartilage. ant: anterior, cb: m. coracobrachialis; clei: cleithrum; clh: m. cleidohumeralis; cr: m. coracoradialis; ds: m. dorsalis scapulae; eh: m. episternohumeralis; epicora: epicoracoid cartilage; hum: humerus; lat: lateral; pa: m. pectoralis portio abdominalis; pc: $\mathrm{m}$. pectoralis portio coracoidea; ps: $\mathrm{m}$. pectoralis portio sternalis; radul: radioulna; rccl: r. coraco-clavicularis; rcb: $r$. coraco-brachialis; rpp: r. pectoralis proprius; shpa: m. scapulohumeralis profundus anterior; sscap: suprascapula; sub: m. subcoracoscapularis; supa: m. supracoracoideus portio anterior; supp: m. supracoracoideus portio posterior 


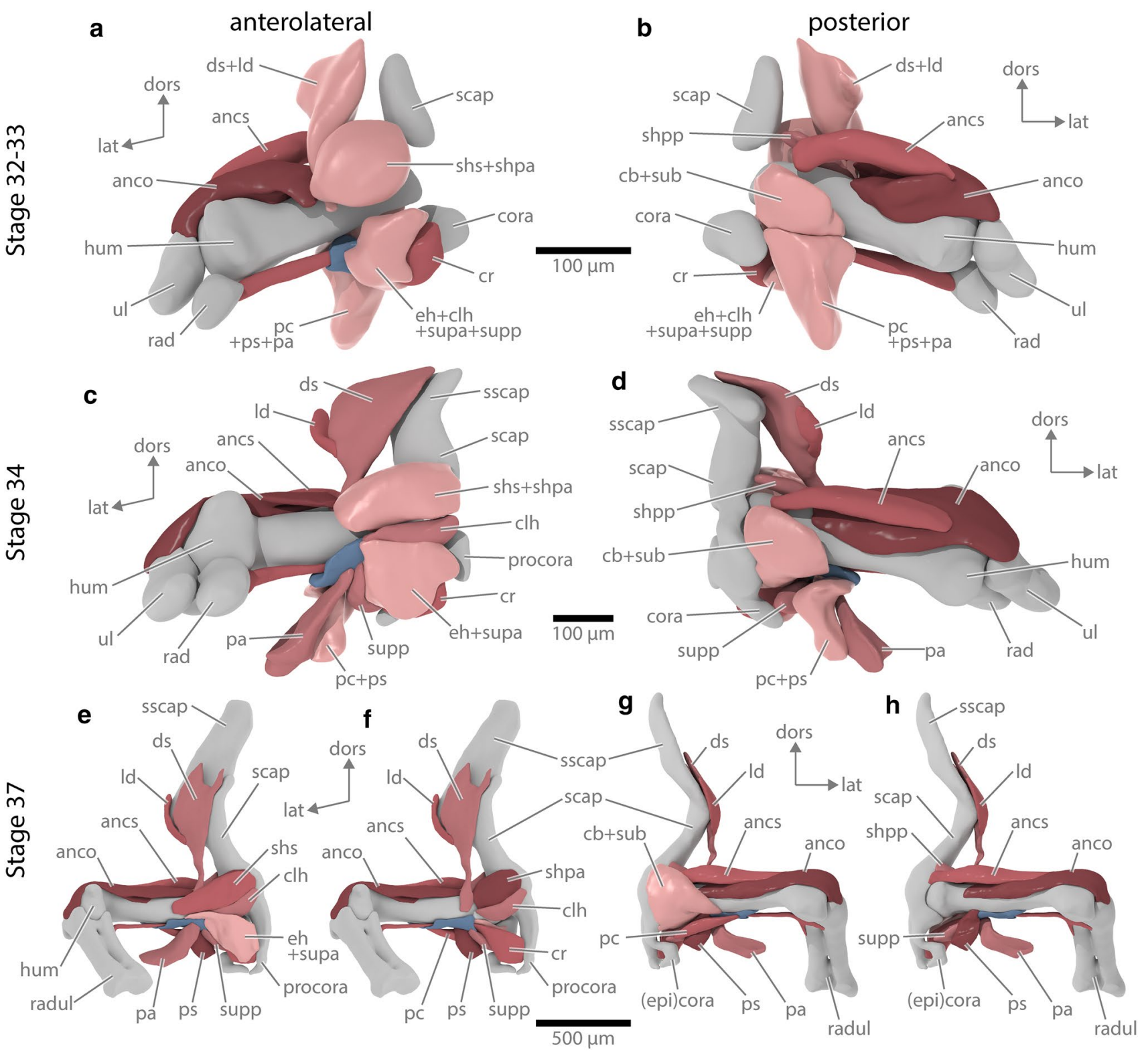

Fig. 7 Ontogenetic development of the shoulder joint muscles in Rhinella marina. Anterolateral (left) and posterior (right) views. Surfaces derived from aligned histological serial sections. Red: muscles (different shades for better visual separation of adjacent muscles); dark blue: connective tissue; light gray: skeletal element with no distinction of bone and cartilage. a-b Stage 32-33 larva (ZMH A14928); separation of $\mathrm{cb}+\mathrm{sub}$ and $\mathrm{pc}+\mathrm{ps}+\mathrm{pa}$ artificial based on differences in the cell differentiation. c-d Stage 34 larva (ZMH A14930). e-h Stage 37 larva (ZMH A14933), muscle layers successively removed. anco: heads of $\mathrm{m}$. anconaeus not crossing the shoulder joint; ancs: $\mathrm{m}$. anconaeus caput scapulare; cb: m. coracobra-

pre-muscle mass, the portio abdominalis of the $\mathrm{m}$. pectoralis was separated from the remaining pre-muscle mass at its origin (Fig. 9f). An anteriorly directed expansion of the premuscle mass represented the future $\mathrm{m}$. cutaneaus pectoris (Fig. 9e); the cell condensation preceding the $\mathrm{m}$. cutaneaus chialis; clh: m. cleidohumeralis; cora: coracoid; cr: m. coracoradialis; dors: dorsal; ds: m. dorsalis scapulae; eh: m. episternohumeralis; epicora: epicoracoid cartilage; hum: humerus; lat: lateral; ld: m. latissimus dorsi; pa: $\mathrm{m}$. pectoralis portio abdominalis; $\mathrm{pc}$ : $\mathrm{m}$. pectoralis portio coracoidea; procora: procoracoid cartilage; ps: $\mathrm{m}$. pectoralis portio sternalis; rad: radius; radul: radioulna; scap: scapula; shs: m. scapulohumeralis superficialis; shpa: $\mathrm{m}$. scapulohumeralis profundus anterior; shpp: m. scapulohumeralis profundus posterior; sscap: suprascapula; sub: m. subcoracoscapularis; supa: m. supracoracoideus portio anterior; supp: $\mathrm{m}$. supracoracoideus portio posterior; ul: ulna

pectoris was posteriorly continuous with the future portionis abdominalis and sternalis of the $\mathrm{m}$. pectoralis. The remaining continuous posteroventral pre-muscle mass represented the portionis sternalis and coracoidea of the $\mathrm{m}$. pectoralis and the $\mathrm{mm}$. coracobrachialis and subcoracoscapularis. 
In Stage 35 (ZMH A14740), the future mm. scapulohumeralis superficialis and profundus anterior were mostly continuous, but formed two distinct heads at their insertions (Fig. 9g) and the m. latissimus dorsi was separated from the $\mathrm{m}$. dorsalis scapulae. Anteroventrally, the mm. episternohumeralis and cleidohumeralis were separated from one another (Fig. 9g) and from the m. supracoracoideus; the latter muscle was more distinct from the $\mathrm{m}$. coracoradialis (Fig. 9h). Posteroventrally, the portio abdominalis of m. pectoralis was entirely distinct from the other portions of this muscle, while the portionis sternalis and coracoidea were separated at their origins, but remained continuous at their insertion (Fig. 9i). The future m. cutaneus pectoris was expanded anteriorly, but, posteriorly, remained continuous with the portionis abdominalis and sternalis of the $\mathrm{m}$. pectoralis (Fig. 9h, i). The mm. coracobrachialis and subcoracoscapularis formed one continuous pre-muscle mass.

In the specimen of Stage 41 (ZMH A12870), the origin of the m. scapulohumeralis superficialis was shifted to the medial surface of the scapula and the anterodorsal part of the lateral coracoid. Thereby, the mm. scapulohumeralis superficialis and profundus anterior were separated at their origins (Fig. 10a, b). The m. cleidohumeralis was divided into two parts that were separated at their origins but continuous at their insertion; the pars profunda originated from the lateral part of the clavicula and the pars superficialis from the acromion (most anteroventral part of the scapula and the ventrally adjacent cartilage; Fig. 10a, b). The pars superficialis of the $\mathrm{m}$. cleidohumeralis was closely associated with the mm. scapulohumeralis superficialis and profundus anterior at its origin (Fig. 10a). Posteriorly, all portions of the $\mathrm{m}$. pectoralis were separated from one another and from the m. cutaneus pectoris (Fig. 10d). The m. coracobrachialis was split into a ventral and a dorsal portion (Fig. 10c), and the portio dorsalis of this muscle was closely associated and mostly continuous with the $\mathrm{m}$. subcoracoscapularis (Fig. 10c, d).

\section{Discussion}

\section{Muscle nomenclature and comparison to literature accounts}

The muscles of the forelimbs in tetrapods are ontogenetically derived from two (ventral and dorsal) pre-muscle masses that form within the developing limb bud (summarized in Hirasawa and Kuratani 2018). These two pre-muscle masses split into the individual limb muscles during morphogenesis (Hirasawa and Kuratani 2018). Although none of the specimens examined herein showed only two undifferentiated pre-muscle masses, the observations presented herein are in accordance with the general pattern of limb muscle development in tetrapods: The various shoulder joint muscle entities present in late developmental stages or adult specimens ontogenetically originated from condensations of pre-muscle cells and formed by subdivisions of the latter. Extrapolating the observed pattern to earlier developmental stages, it seems likely that the $\mathrm{mm}$. anconaeus, dorsalis scapulae, latissimus dorsi, and the group of scapulohumeralis muscles are derived from a single dorsal pre-muscle mass hypothesized to be present in all tetrapods. Likewise, a single ventral pre-muscle mass presumably gives rise to the $\mathrm{mm}$. cleidohumeralis, episternohumeralis, supracoracoideus, coracoradialis, subcoracoscapularis, coracobrachialis, and pectoralis (Fig. 11).

Regarding the muscles derived from the dorsal pre-muscle mass, our observations on the mm. anconaeus (all heads), dorsalis scapulae, and latissimus dorsi are in line with previous anatomical descriptions of Ascaphus truei, Rana, and Bufo bufo (Ritland 1955; Gaupp 1896; Bigalke 1927, respectively; Table 2). The m. scapulohumeralis superficialis usually is considered to be a part (pars scapularis sensu Bigalke 1927) of the m. deltoideus. The mm. episternohumeralis (pars cleido-humeralis longus sensu Bigalke 1927; pars episternalis sensu Gaupp 1896) and cleidohumeralis (pars clavicularis sensu Bigalke 1927) represent the other parts of the m. deltoideus in other studies; our results, however, indicate that the different muscle units that constitute the $\mathrm{m}$. deltoideus in other studies, in fact, have different ontogenetic origins, namely either the ventral or the dorsal pre-muscle mass. Because of these different ontogenetic origins of the different parts, denoting them as parts of one muscle (m. deltoideus) might be misleading. Given that the muscle mass called m. scapulohumeralis superficialis herein is closely associated (ontogenetic development, innervation, and, in most species, continuity at origin) with the m. scapulohumeralis profundus anterior, it seems expedient and justified to discard its old name ' $m$. deltoideus pars scapularis'. This also applies to the other muscles commonly considered to be a part of the m. deltoideus (suggested names summarized in Table 2).

Gaupp (1896) neither observed the m. scapulohumeralis profundus anterior, nor the $\mathrm{m}$. scapulohumeralis profundus posterior in different species of Rana. Our analyses, however, confirmed the presence of both muscles in R. temporaria and support the notion of Bigalke (1927) that the $m$. deltoideus pars scapularis described by Gaupp (1896) also comprised the $\mathrm{m}$. scapulohumeralis profundus anterior. Further support for this hypothesis can be found in Gaupp's (1896) descriptions: he reported two separate origins and insertions for the pars scapularis and those origins correspond to the origins and insertions of the mm. scapulohumeralis superficialis and profundus anterior observed herein. In addition, Gaupp (1896) observed that some fibers of his m. deltoideus pars scapularis were innervated by the $r$. 

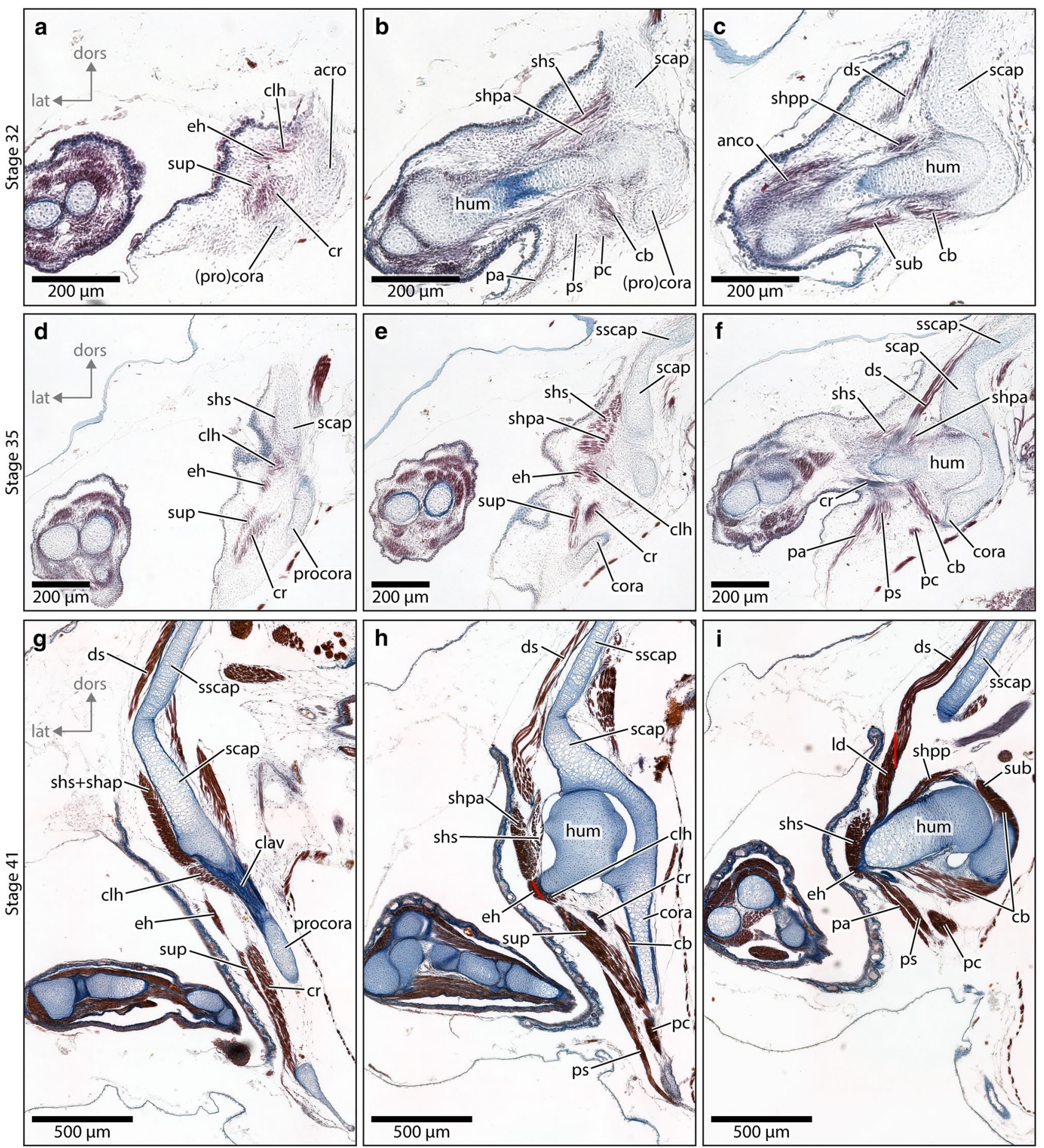

Fig. 8 Azan-stained histological sections of the shoulder joint region of Bombina orientalis larvae in different developmental stages. Left section is located anterior to the middle section, which, in turn, is anterior to the right. a-c Sections of Stage 32 (ZMH A12427), leftside shoulder joint, but mirrored to the right for consistency. d-f Sections of Stage 35 (ZMH A12429), right-side shoulder joint. g-i Sections of Stage 41 (ZMH A12435), right-side shoulder joint. Red line: separation of adjacent muscles. anco: heads of $\mathrm{m}$. anconaeus not crossing the shoulder joint; cb: m. coracobrachialis; clav: clavicula; clh: m. cleidohumeralis; cora: coracoid; cr: m. coracoradialis; dors: dorsal; ds: m. dorsalis scapulae; eh: m. episternohumeralis; hum: humerus; ld: $\mathrm{m}$. latissimus dorsi; lat: lateral; pa: m. pectoralis portio abdominalis; pc: m. pectoralis portio coracoidea; procora: procoracoid cartilage; ps: m. pectoralis portio sternalis; scap: scapula; sub: $\mathrm{m}$. subcoracoscapularis; shs: $\mathrm{m}$. scapulohumeralis superficialis; shpa: $\mathrm{m}$. scapulohumeralis profundus anterior; shpp: m. scapulohumeralis profundus posterior; sscap: suprascapula; sup: m. supracoracoideus 

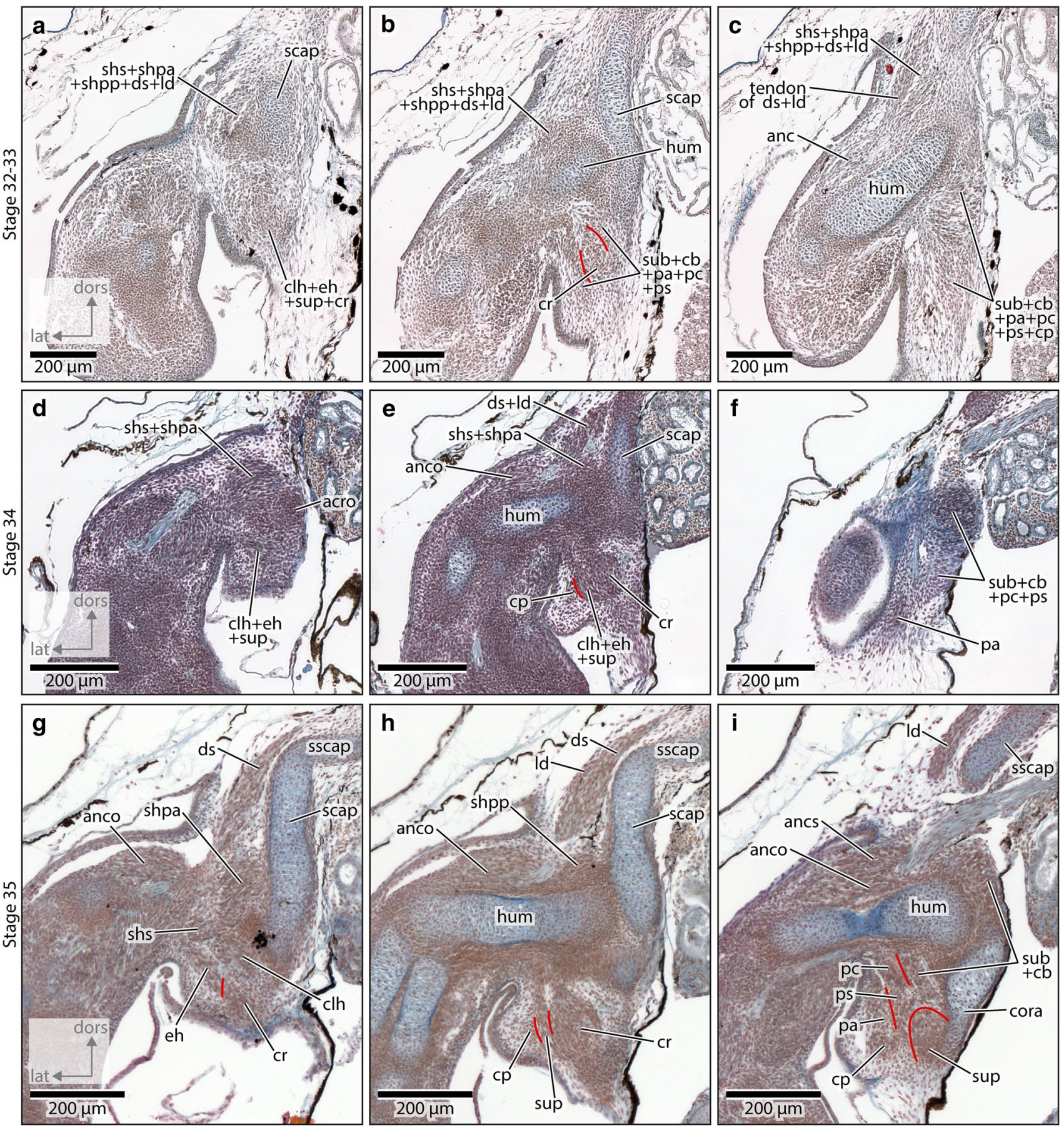

Fig. 9 Azan-stained histological sections of the right shoulder joint region of Rana temporaria larvae in different developmental stages. Left section is located anterior to the middle section, which, in turn, is anterior to the right. a-c Sections of Stage 32-33 (ZMH A14736). d-e Sections of Stage 34 (ZMH A14739). g-i Sections of Stage 35 (ZMH A14740). Red line: separation of adjacent muscles. anc: $\mathrm{m}$. anconaeus; anco: heads of $\mathrm{m}$. anconaeus not crossing the shoulder joint; ancs: m. anconaeus caput scapulare; cb: m. coracobrachialis; clh: m. cleidohumeralis; cora: coracoid; cp: $\mathrm{m}$. cutaneus pectoris; cr: m. coracoradialis; dors: dorsal; ds: m. dorsalis scapulae; eh: m. episternohumeralis; hum: humerus; ld: m. latissimus dorsi; lat: lateral; pa: m. pectoralis portio abdominalis; pc: m. pectoralis portio coracoidea; procora: procoracoid cartilage; ps: $\mathrm{m}$. pectoralis portio sternalis; scap: scapula; sub: m. subcoracoscapularis; shs: m. scapulohumeralis superficialis; shpa: m. scapulohumeralis profundus anterior; shpp: $\mathrm{m}$. scapulohumeralis profundus posterior; sscap: suprascapula; sup: $\mathrm{m}$. supracoracoideus 
coraco-clavicularis, which contradicts our observations that this ramus only supplies muscles derived from the ventral pre-muscle mass. It seems likely that those fibers of Gaupp's (1896) pars scapularis that are supplied by the r. coracoclavicularis correspond to the pars superficialis of the $\mathrm{m}$. cleidohumeralis due to the pattern of innervation and the observed close association of the pars superficialis with the $\mathrm{m}$. scapulohumeralis superficialis in $R$. temporaria. If this was true, the pars scapularis of the m. deltoideus in Gaupp (1896) would comprise the mm. scapulohumeralis superficialis, scapulohumeralis profundus anterior, and the pars superficialis of the $\mathrm{m}$. cleidohumeralis recognized herein. The pars clavicularis in Gaupp (1896) would be homologous to the pars profunda of the $\mathrm{m}$. cleidohumeralis herein (Table 2), which would be consistent with the position and innervation of these muscles.
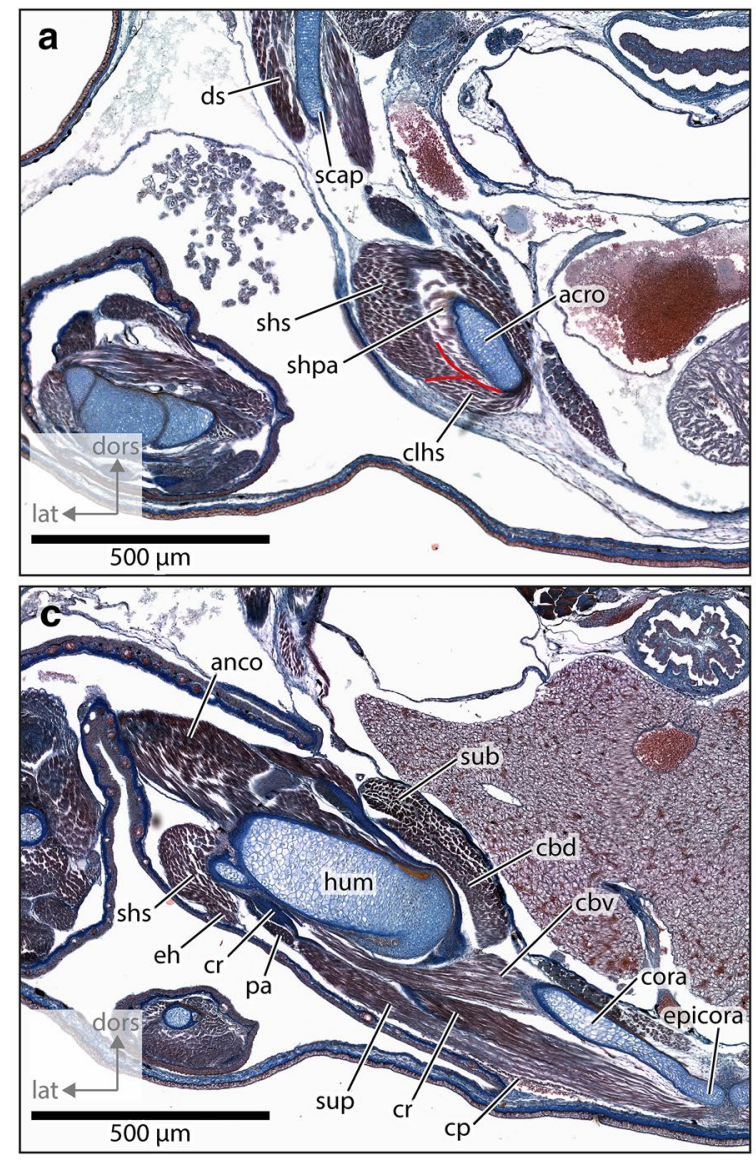

Fig. 10 Azan-stained histological sections of the right shoulder joint region of a Stage 41 larva of Rana temporaria. a-d Sections from anterior to posterior. Red line: separation of adjacent muscles. acro: acromion; anco: heads of $\mathrm{m}$. anconaeus not crossing the shoulder joint; ancs: $m$. anconaeus caput scapulare; cbd: $m$. coracobrachialis pars dorsalis; cbv: m. coracobrachialis pars ventralis; clav: clavicula; clhp: $\mathrm{m}$. cleidohumeralis pars profunda; clhs: $\mathrm{m}$. cleidohumeralis pars superficialis; cora: coracoid; cp: $\mathrm{m}$. cutaneus pectoris; cr: m. cora-
The single, undivided muscle mass (called $\mathrm{m}$. deltoideus by Ritland 1955) observed in Ascaphus truei is formed by the $\mathrm{mm}$. episternohumeralis, cleidohumeralis, and scapulohumeralis superficialis. The contribution of these latter three muscles to the formation of the former one muscle mass is supported by its absolute and relative position and by the muscle mass being supplied by the nerve branches that usually innervate these three muscles (rr. coraco-clavicularis and dorsalis scapulae anterior; own observations; Ritland 1955). Given that the $\mathrm{m}$. scapulohumeralis superficialis is ontogenetically derived from the dorsal, whereas the $\mathrm{mm}$. episternohumeralis and cleidohumeralis are derived from the ventral pre-muscle mass, the most parsimonious explanation for the condition observed in A. truei is that the mm. episternohumeralis and cleidohumeralis did not separate during ontogenesis and are secondarily fused to the m. scapulohumeralis superficialis. This is supported by a previous

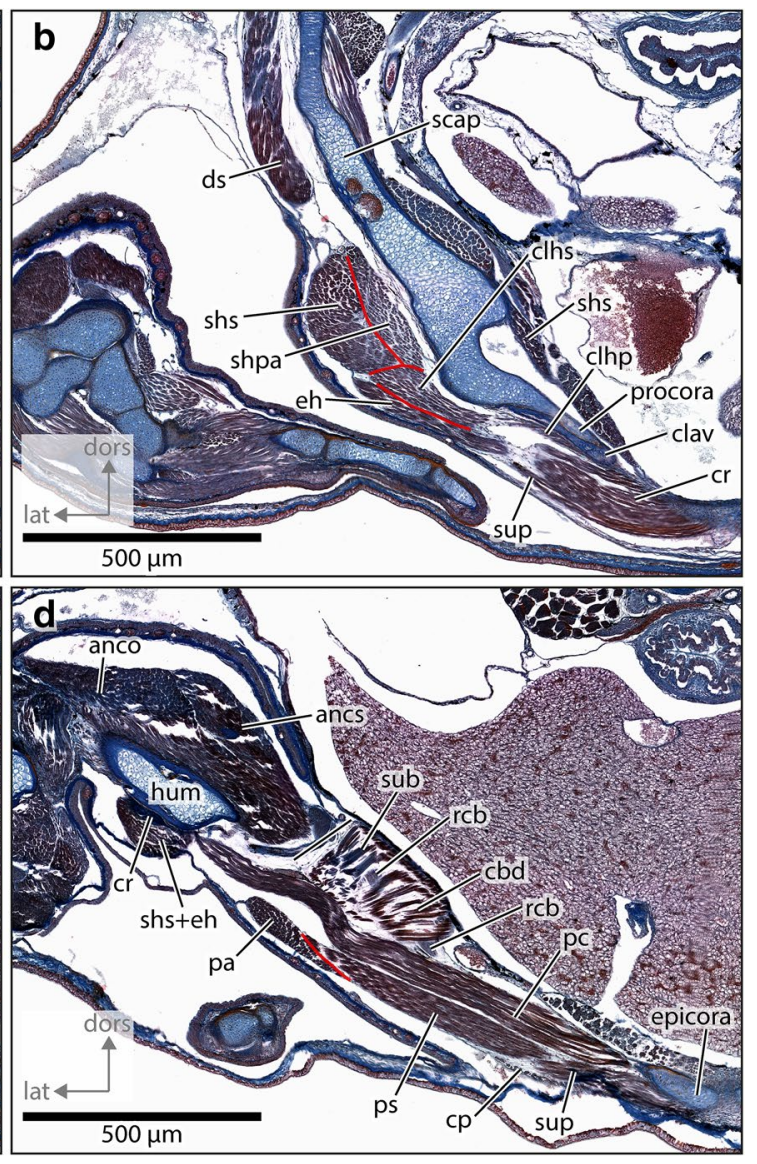

coradialis; dors: dorsal; ds: m. dorsalis scapulae; eh: m. episternohumeralis; epicora: epicoracoid cartilage; hum: humerus; lat: lateral; pa: m. pectoralis portio abdominalis; pa: m. pectoralis portio abdominalis; pc: $m$. pectoralis portio coracoidea; procora: procoracoid cartilage; ps: m. pectoralis portio sternalis; rcb: r. coraco-brachialis; scap: scapula; sub: m. subcoracoscapularis; shs: m. scapulohumeralis superficialis; shpa: m. scapulohumeralis profundus anterior; sup: $\mathrm{m}$. supracoracoideus 
observation that the corresponding muscle mass in Leiopelma, phylogenetically a close relative of Ascaphus, consisted of somewhat more distinct portions (Ritland 1955),

The muscle superficial (ventral) to the $\mathrm{m}$. coracoradialis has previously been denoted as the pars epicoracoidea of the m. pectoralis (Gaupp 1896; Bigalke 1927) and as the $\mathrm{m}$. supracoracoideus (Ritland 1955). We observed that the pre-muscle mass (anteroventral) that gave rise to this muscle separated from the pre-muscle mass (posteroventral) that gave rise to the other portions of the $\mathrm{m}$. pectoralis early in ontogeny (Fig. 11). We suggest the use of the term 'm. supracoracoideus' instead of denoting this muscle as a portion of the $\mathrm{m}$. pectoralis to highlight the split from the pectoralis group early in ontogeny (Table 2).

We further observed that the $\mathrm{m}$. supracoracoideus split into an anterior and a posterior portion during the ontogenesis in Rhinella marina; there was no connection or association of this muscle to the $\mathrm{m}$. coracobrachialis. The posterior portion of the m. supracoracoideus resembles the pars superficialis of the m. coraco-brachialis brevis in the descriptions and illustrations of Bufo bufo by Bigalke (1927) with regard to the locations of the origin and the insertion on the skeletal elements and relative to other muscles. Therefore, we hypothesize that they are homologous. If so, the $\mathrm{m}$. coracobrachialis would be present with only one portion in $R$. marina and B. bufo. In contrast, the ontogenetic pattern observed in Rana temporaria indicated that the m. coracobrachialis is present with two parts in that species: the separation of the two parts (dorsal and ventral) of the $\mathrm{m}$. coracobrachialis occurred in a later developmental stage than the separation of their common precursor from the precursor of the m. supracoracoideus (Fig. 11). In the light of the evidence, we consider it most parsimonious to assume that the partis dorsalis and ventralis, thus, truly are derivatives of the $\mathrm{m}$. coracobrachialis in $R$. temporaria and neither of them is homologous to the muscle denoted $\mathrm{m}$. coraco-brachialis brevis pars superficialis by Bigalke (1927) in B. bufo.

Ritland (1955) reported the presence of a superficial and a profound supracoracoideus muscle in A. truei. Our observations revealed that the muscle unit called $\mathrm{m}$. supracoracoideus profundus by Ritland (1955) was located dorsal (profound) to the anastomosis formed by branches of the rr. coraco-clavicularis and coraco-brachialis. Given that a similar anastomosis was observed in Alytes obstetricans (Fig. 2) and Bombina orientalis, and that only the m. coracobrachialis was located dorsal to the nerve branch in those two species, we suggest that the $\mathrm{m}$. supracoracoideus profundus observed by Ritland (1955) in fact represents a part (pars ventralis) of the $\mathrm{m}$. coracobrachialis. This interpretation is also consistent with the position of the insertion of $\mathrm{mm}$. supracoracoideus and coracobrachialis relative to the $\mathrm{m}$. coracoradialis: the fibers of the $\mathrm{m}$. supracoracoideus were

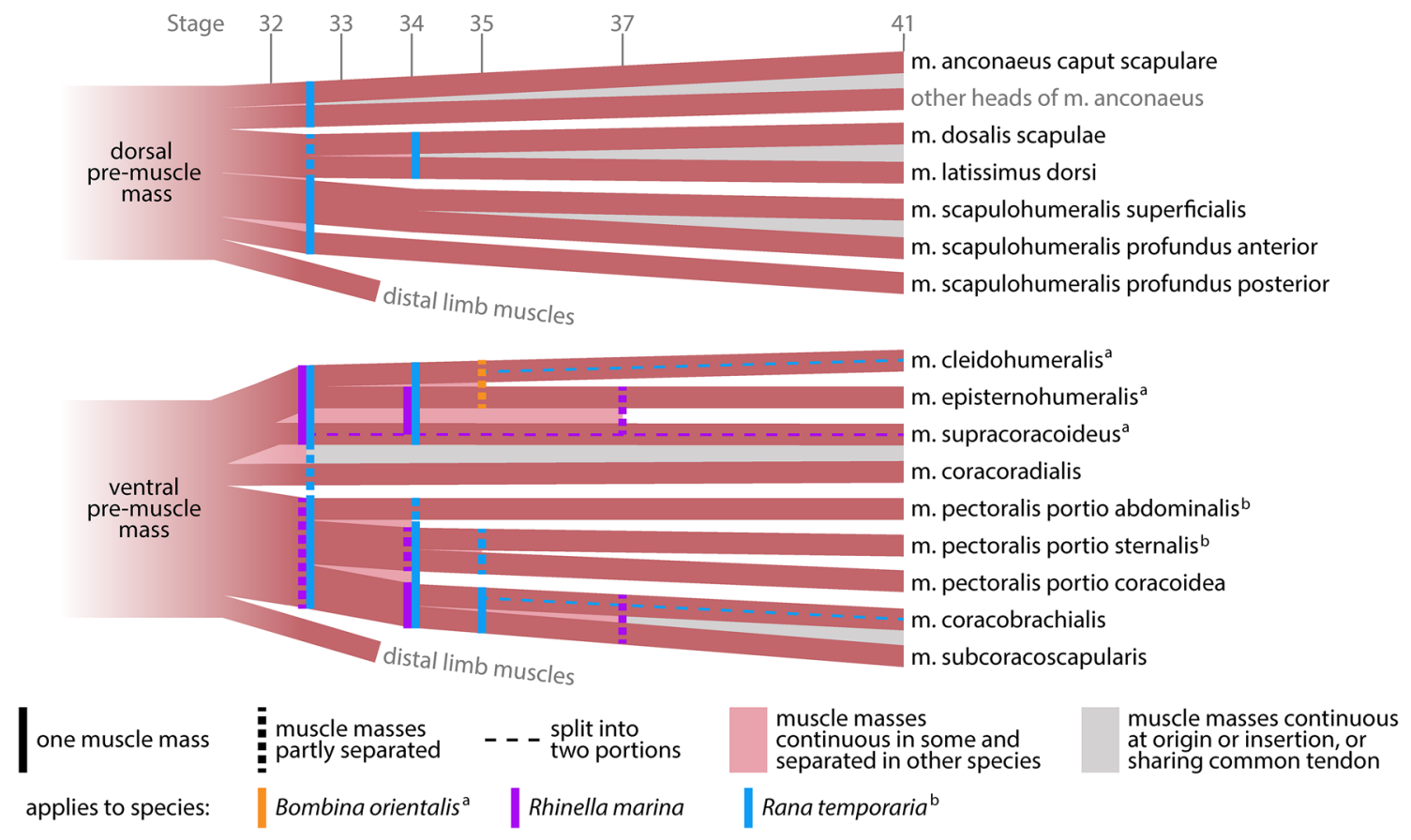

Fig. 11 Generalized ontogenetic splitting pattern of pre-muscle masses located ventral and dorsal to the humerus. Timelines derived from larvae of Rhinella marina (Stages 32-33, 34, 37, 41), Rana temporaria (Stages 32-33, 34, 35, 41), and Bombina orientalis (Stage 32 only). ${ }^{a} B$. orientalis only used to derive the splitting pattern of mm. cleidohumeralis, episternohumeralis, and supracoracoideus, as all other muscles were already distinct in the earliest stage examined, which is neglected in this figure. ${ }^{\mathrm{b}}$ In $R$. temporaria, the $\mathrm{m}$. cutaneus pectoris (not included in illustration) separated from the portionis sternalis and abdominalis of the $\mathrm{m}$. pectoralis 
located ventral (superficial) to the m. coracoradialis and inserted onto the connective tissue covering the tendon of the latter, whereas the fibers of the $\mathrm{m}$. coracobrachialis laid dorsal (profound) to the $\mathrm{m}$. coracoradialis and inserted onto the posterior surface of the crista ventralis and the humerus (observed in A. obstetricnas, B. orientalis, Rhinella marina, and Rana temporaria; Figs. 2, 6, Supporting Information Fig. S2). The insertions of the mm. supracoracoideus and coracobrachialis are, thus, separated by (the tendon of) the $\mathrm{m}$. coracoradialis. If the muscle called $\mathrm{m}$. supracoracoideus profundus by Ritland (1955) would be considered as a part of the $\mathrm{m}$. coracobrachialis, the positions of the insertions of the $\mathrm{mm}$. coracobrachialis and supracoracoideus relative to the $\mathrm{m}$. coracoradialis would be identical to the conditions observed in the other species. If not, the insertion of the m. supracoracoideus profundus (sensu Ritland 1955) would have shifted compared to the other species.

We observed that the muscle unit, which has commonly been denoted as m. coraco-brachialis longus (Gaupp 1896; Bigalke 1927), was ontogenetically derived from the muscle precursor that also gave rise to the portionis sternalis and abdominalis of the $\mathrm{m}$. pectoralis in Rhinella marina and likely also in Rana temporaria. We therefore consider this muscle to be a portion of the $\mathrm{m}$. pectoralis and suggest reflecting this relation by denoting it as the portio coracoidea of the m. pectoralis (Table 2). There were, however, some observations that render the suggested assignment to the $\mathrm{m}$. pectoralis ambiguous: In some species (Alytes obstetricans and Rana temporaria), the portio coracoidea received nerve supply from the r. coraco-brachialis, and in Ascalphusi truei form the rr. coraco-brachialis and pectoralis proprius, which could imply a close association of the portio coracoidea of the m. pectoralis with the $\mathrm{m}$. coraco-brachialis. Some ambiguity remains that requires more research, but at the moment, we consider the relationship to the $\mathrm{m}$. pectoralis more plausible because of layer, position, and ontogenetic origin.

The $\mathrm{m}$. cutaneous pectoris was only present in R. temporaria and was ontogenetically derived from a shared anlage with the portionis sternalis and abdominalis of the m. pectoralis. This raises the question, if these portions of the pectoralis are homologous across the considered species or if such a homologization should include the $\mathrm{m}$. cutaneous pectoris as some kind of de novo portion of the m. pectoralis.

Ritland (1955) described a m. subcoracoscapularis in $A$. truei. Neither Gaupp (1896), nor Bigalke (1927) described a muscle of this name in Rana and Bufo bufo, respectively. Gaupp (1896), however, observed that a similar muscle, that he denoted the pars profunda of $\mathrm{m}$. corcaco-brachialis, was pierced by the r. coraco-brachialis, and Bigalke (1927) reported two insertions (humeral spina tuberculi medialis and crista ventralis humeri) for the same muscle. Our results revealed the presence of the $\mathrm{m}$. subcoracoscapularis in these species. Given that we observed the mm. subcoracoscapularis and coracobrachialis to always be continuous at their origins, that these two muscles were mostly continuous in $R$. temporaria, and that the r. coraco-brachialis passed between these two muscles, we assume that the pars profunda of $\mathrm{m}$. coraco-brachialis described by Gaupp (1896) and Bigalke (1927) comprises the m. subcoracoscapularis (Table 2). If so, the pars profunda of $\mathrm{m}$. coraco-brachialis described by Gaupp (1896) and Bigalke (1927) would not be homologous to the m. coracobrachialis herein. To avoid confusion, we suggest referring to the parts of the $\mathrm{m}$. coracobrachialis as pars dorsalis and pars ventralis, respectively.

\section{Limitations}

Our sampling of developmental stages was sparse and each of the developmental stages was represented by only one specimen per species. The observed differences in the timing of the developmental events (splitting of muscle units) may be subject to individual (within-species) variations and might not represent interspecific variation. Yet, interspecific differences in the timing of the development of the pectoral girdle skeleton (Baleeva 2001) and its muscles (Soliz et al. 2018) have previously been reported for other anuran species.

The innervation patterns of the shoulder joint muscles were described using one specimen per species only and the observed differences between species might be caused by individual variations rather than species-specific peculiarities. The presence of sexual dimorphism has been observed for the humerus (Lee 2001; Padhye et al. 2015; Petrović et al. 2017) and certain muscles attached to the pectoral girdle (Oka et al. 1984; Emerson 1990; Lee 2001) in some anuran species. Sexual dimorphism and how the observed patterns are modified in a gender-specific fashion need further investigation.

Although we are aware of these limitations, we believe that our sample was large enough to reach our primary aim, namely to identify the different shoulder joint muscles and to assess their interspecific homologies by considering the ontogeny and innervation. We do believe so, because our observations were consistent across developmental stages within a given species and between closely related species, and allowed for assessing the ontogenetic splitting pattern of (pre-)muscle masses. Having reached our primary aim, we hesitated to add more specimens to our sample, because we expected limited additional insights but relatively high costs in terms of time investment. The addition of younger developmental stages, in particular, appeared unnecessary to us as the included specimens were sufficient to identify homologous (pre-) 
muscle masses across species and because the (pre-)muscle configurations in early stages can be complemented from literature accounts.

\section{Summary and conclusion}

The anuran mm. anconaeus, dorsalis scapulae, latissimus dorsi, coracoradialis, and the portionis sternalis and abdominalis of the $\mathrm{m}$. pectoralis have consistently been recognized and denoted in the previous studies (Gaupp 1896; Bigalke 1927; Ritland 1955) and are reassessed herein. The muscle unit called $\mathrm{m}$. coraco-brachialis longus in previous studies has also been consistently recognized, but the name for this muscle is misleading as it suggests a close relation to the $\mathrm{m}$. coracobrachialis (as used herein), whereas it is ontogenetically closely associated with the portionis sternalis and abdominalis of the $\mathrm{m}$. pectoralis. The name 'pectoralis portio coracoidea' seems more appropriate. The muscle entities that were previously considered as parts of a m. deltoideus ontogenetically arise from different pre-muscle masses (ventral and dorsal) observed in the early development of the tetrapod limb bud (Hirasawa and Kuratani 2018). This composite nature of the 'm. deltoideus', in our opinion, warrants alternative terms (i.e., mm. scapulohumeralis superficialis, cleidohumeralis, and episternohumeralis) that better clarify the independent nature of the muscle entities. The $\mathrm{m}$. scapulohumeralis superficialis is closely associated with the $\mathrm{m}$. supracoracoideus profundus anterior and both these muscles have occasionally been described as one muscle; the $\mathrm{m}$. supracoracoideus profundus posterior likely has been overlooked by some authors. The $\mathrm{m}$. subcoracoscaplualris, although mostly inseparable from the $\mathrm{m}$. coracobrachialis in Rana temporaria, is present in all species examined and is characterized by being superficial to the $\mathrm{m}$. coracobrachialis and the r. coraco-brachialis. The mm. cleidohumeralis, supracoracoideus, and coracobrachialis are present with two parts or portions in some species, these portions have not always been recognized and assigned correctly in the previous studies.

In our study, we applied homology criteria to sort and clarify the inconsistencies in the literature. Bearing the same term is not a prerequisite per se to establish a homology statement for two entities. It is our experience, however, that the previously applied terms and contradictions in the literature obstructed the understanding of the evolution of the shoulder joint muscles. The terminology which we propose mostly recruits from existing terms and tries to limit changes to the necessary. It clarifies, in our opinion, many discrepancies, and offers more parsimonious explanations of the observed patterns than previous systems. This case study highlights the importance of critically questioning published anatomical descriptions before they are used for comparisons in other studies. For example, the observation that the muscles commonly considered to be parts of the $\mathrm{m}$. deltoideus are ontogenetically derived from different pre-muscle masses renders the overall homologization of 'the m. deltoideus' with single muscles or muscle complexes in other vertebrate taxa questionable. In our opinion, only well-supported homologization and primary homology statements of muscle units across taxa allow for the reliable reconstruction of ancestral character states and should be scrutinized before they were used to derive evolutionary hypotheses or conclusions.

Supplementary Information The online version contains supplementary material available at https://doi.org/10.1007/s00435-020-00510-4.

Acknowledgements We are grateful to Katharina Ruthsatz for providing larvae of Rana temporaria, André Beerlink and YXLON International $\mathrm{GmbH}$ for performing the $\mu \mathrm{CT}$ scans of Bufo bufo, and Thomas Kleinteich and the TPW Prüfzentrum GmbH for performing the $\mu \mathrm{CT}$ scan of Rhinella marina. In addition, we thank Frank Friedrich for fruitful discussions, and Carla Viola Reinbold and Dilara Leptin for their help with digitizing the histological serial sections. We also thank Lennart Olsson for the time invested in the review and the very helpful comments that greatly improved the manuscript. This study was funded by the Deutsche Forschungsgemeinschaft (DFG, German Research Foundation) -387723284 .

Author contributions KE conceived the study, curated and analyzed the data, performed the $3 \mathrm{~d}$ reconstructions, and drafted the manuscript. $\mathrm{KE}$ and SP generated the volume data. KE, SP, and AH discussed the results. AH provided resources, edited an early version of the manuscript, and acquired funding. All authors critically revised the manuscript and approved the final version.

Funding Open Access funding enabled and organized by Projekt DEAL. This study was funded by the Deutsche Forschungsgemeinschaft (DFG, German Research Foundation) - 387723284.

Data availability The volume data generated for the study are accessible at https://www.fdr.uni-hamburg.de; DOIs are provided in Table 1.

\section{Compliance with ethical standards}

Conflicts of interest The authors declare that they have no conflict of interest.

Ethics approval This study does not contain any experiments with human participants or living animals performed by any of the authors.

Open Access This article is licensed under a Creative Commons Attribution 4.0 International License, which permits use, sharing, adaptation, distribution and reproduction in any medium or format, as long as you give appropriate credit to the original author(s) and the source, provide a link to the Creative Commons licence, and indicate if changes were made. The images or other third party material in this article are included in the article's Creative Commons licence, unless indicated otherwise in a credit line to the material. If material is not included in the article's Creative Commons licence and your intended use is not 
permitted by statutory regulation or exceeds the permitted use, you will need to obtain permission directly from the copyright holder. To view a copy of this licence, visit http://creativecommons.org/licenses/by/4.0/.

\section{References}

Abdala V, Diogo R (2010) Comparative anatomy, homologies and evolution of the pectoral and forelimb musculature of tetrapods with special attention to extant limbed amphibians and reptiles. J Anat 217:536-573. https://doi.org/10.1111/j.1469-7580.2010.01278.x

Baleeva NV (2001) Formation of the scapular part of the pectoral girdle in anuran larvae. Russ J Herpetol 8:195-204

Baleeva NV (2009) Formation of the coracoid region of the anuran pectoral girdle. Russ J Herpetol 16:41-50

Bigalke R (1927) Zur Myologie der Erdkröte. (Bufo vulgaris, Laurenti.). Z Anat Entwickl Gesch 82:286-353. https://doi. org/10.1007/BF02119515

Burton TC (1983) The musculature of the papuan frog Phrynomantis stictogaster (Anura, Microhylidae). J Morphol 175:307-324. https ://doi.org/10.1002/jmor.1051750308

Cardona A, Saalfeld S, Schindelin J, Arganda-Carreras I, Preibisch S, Longair M, Tomancak P, Hartenstein V, Douglas RJ, Samuel A (2012) TrakEM2 software for neural circuit reconstruction. PLoS ONE 7:e38011. https://doi.org/10.1371/journal.pone.0038011

Coates MI, Jeffery JE, Rut M (2002) Fins to limbs: what the fossils say. Evol Dev 4:390-401. https://doi.org/10.1046/j.1525142X.2002.02026.X

Cunningham DJ (1890) The value of nerve-supply in the determination of muscular homologies and anomalies. J Anat Physiol 25:31-40

de Pinna MCC (1991) Concepts and tests of homology in the cladistic paradigm. Cladistics 7:367-394. https://doi. org/10.1111/j.1096-0031.1991.tb00045.x

Diogo R, Abdala V (2007) Comparative anatomy, homologies and evolution of the pectoral muscles of bony fish and tetrapods: a new insight. J Morphol 268:504-517. https://doi.org/10.1002/ jmor. 10531

Diogo R, Ziermann JM (2014) Development of fore- and hindlimb muscles in frogs: morphogenesis, homeotic transformations, digit reduction, and the forelimb-hindlimb enigma. J Exp Zool B Mol Dev Evol 322:86-105. https://doi.org/10.1002/jez.b.22549

Diogo R, Johnston P, Molnar JL, Esteve-Altava B (2016) Characteristic tetrapod musculoskeletal limb phenotype emerged more than 400 MYA in basal lobe-finned fishes. Sci Rep 6:37592. https://doi. org/10.1038/srep37592

Duellman WE, Trueb L (1994) Biology of amphibians, Johns Hopkins Paperbacks. Johns Hopkins University Press, Baltimore

Emerson SB (1990) Scaling of the epicoracoid horn muscle in arciferal frogs. J Herpetol 24:84-87

Engelkes K, Friedrich F, Hammel JU, Haas A (2018) A simple setup for episcopic microtomy and a digital image processing workflow to acquire high-quality volume data and 3D surface models of small vertebrates. Zoomorphology 137:213-228. https://doi. org/10.1007/s00435-017-0386-3

Engelkes K, Kath L, Kleinteich T, Hammel JU, Beerlink A, Haas A (2020) Ecomorphology of the pectoral girdle in anurans (Amphibia, Anura): shape diversity and biomechanical considerations. Ecol Evol 10:11467-11487. https://doi.org/10.1002/ ece 3.6784

Gaupp EWT (1896) A. Ecker's und R. Wiedersheim's Anatomie des Frosches. Erste Abteilung. Lehre vom Skelett und vom Muskelsystem, 3rd edn. Friedrich Vieweg und Sohn, Braunschweig

Gaupp EWT (1899) A. Ecker's und R. Wiedersheim's Anatomie des Frosches. Zweite Abteilung. Lehre vom Nerven- und Gefässsystem, $2^{\text {nd }}$ edn. Friedrich Vieweg und Sohn, Braunschweig
Gegenbaur C (1865) Untersuchungen zur vergleichenden Anatomie der Wirbelthiere: Zweites Heft - Schultergürtel der Wirbelthiere, Brustflosse der Fische. Wilhem Engelmann, Leipzig

Gosner KL (1960) A simplified table for staging anuran embryos and larvae with notes on identification. Herpetologica 16:183-190

Haines RW (1935) A consideration of the constancy of muscular nerve supply. J Anat 70:33-55

Havelková P, Roček Z (2006) Transformation of the pectoral girdle in the evolutionary origin of frogs: insights from the primitive anuran Discoglossus. J Anat 209:1-11. https://doi.org/10.111 1/j.1469-7580.2006.00583.x

Hirasawa T, Kuratani S (2018) Evolution of the muscular system in tetrapod limbs. Zoological Lett 4:2107. https://doi.org/10.1186/ s40851-018-0110-2

Holliday CM, Witmer LM (2007) Archosaur adductor chamber evolution: integration of musculoskeletal and topological criteria in jaw muscle homology. J Morphol 268:457-484. https://doi. org/10.1002/jmor.10524

Jetz W, Pyron RA (2018) The interplay of past diversification and evolutionary isolation with present imperilment across the amphibian tree of life. Nat Ecol Evol 2:850-858. https://doi.org/10.1038/ s41559-018-0515-5

Jones EI (1933) Observations on the pectoral musculature of Amphibia Salientia. Ann Mag Nat Hist 12:403-420. https://doi. org/10.1080/00222933308673704

Kerr NS (1955) The homologies and nomenclature of the thigh muscles of the opossum, cat rabbit, and rhesus monkey. Anat Rec 121:481-493. https://doi.org/10.1002/ar.1091210302

Krell F-T, Cranston PS, Krell F-T (2004) Which side of the tree is more basal? Syst Entomol 29:279-281. https://doi.org/10.111 1/j.0307-6970.2004.00262.x

Lee J (2001) Evolution of a secondary sexual dimorphism in the toad, Bufo marinus. Copeia 2001:928-935. https://doi. org/10.1643/0045-8511(2001)001[0928:EOASSD]2.0.CO;2

Maglia AM, Púgener LA (1998) Skeletal development and adult osteology of Bombina orientalis (Anura: Bombinatoridae). Herpetologica 54:344-363

Mahendra BC (1936) A case of polymely in the Indian bull-frog, Rana tigrina Daud. Proc Indian Natl Sci Acad B Biol Sci 4:483-493. https://doi.org/10.1007/BF03051421

Manzano A, Abdala V, Herrel A (2008) Morphology and function of the forelimb in arboreal frogs: specializations for grasping ability? J Anat 213:296-307. https://doi.org/10.111 1/j.1469-7580.2008.00929.x

McGonnell IM (2001) The evolution of the pectoral girdle. J Anat 199:189-194. https://doi.org/10.1046/j.1469-7580.2001.19910 189.x

Metscher BD (2009) MicroCT for comparative morphology: simple staining methods allow high-contrast $3 \mathrm{D}$ imaging of diverse nonmineralized animal tissues. BMC Physiol 9:1-14. https://doi. org/10.1186/1472-6793-9-11

Minkoff EC (1974) The Fürbringer hypothesis of nerve-muscle specificity reexamined with respect to the facial musculature. Can J Zool 52:525-532. https://doi.org/10.1139/z74-065

Molnar JL, Diogo R, Hutchinson JR, Pierce SE (2018) Reconstructing pectoral appendicular muscle anatomy in fossil fish and tetrapods over the fins-to-limbs transition. Biol Rev 93:1077-1107. https:// doi.org/10.1111/brv. 12386

Oka Y, Ohtani R, Satou M, Ueda K (1984) Sexually dimorphic muscles in the forelimb of the Japanese toad, Bufo japonicus. J Morphol 180:297-308. https://doi.org/10.1002/jmor.1051800310

Omland KE, Cook LG, Crisp MD (2008) Tree thinking for all biology: the problem with reading phylogenies as ladders of progress. BioEssays 30:854-867. https://doi.org/10.1002/bies.20794

Padhye AD, Jadhav A, Sulakhe S, Dahanukar N (2015) Sexual dimorphism in the Kudremukh Bush Frog (Anura: Rhacophoridae: 
Raorchestes tuberohumerus) of the Western Ghats, India, with a note on its distribution and conservation status. J Threat Taxa 7:7211-7222. https://doi.org/10.11609/JoTT.04192.7211-22

Petrović TG, Vukov TD, Tomašević Kolarov N (2017) Morphometric ratio analyses: locomotor mode in anurans. C R Biol 340:250257. https://doi.org/10.1016/j.crvi.2017.02.004

Ponomartsev S, Valasek P, Patel K, Malashichev Y (2017) Neural crest contribution to the avian shoulder girdle and implications to girdle evolution in vertebrates. Biol Commun 62:26-37. https://doi. org/10.21638/11701/spbu03.2017.104

Púgener LA, Maglia AM (1997) Osteology and skeletal development of Discoglossus sardus (Anura: Discoglossidae). J Morphol 233:267-286. https://doi.org/10.1002/(SICI)1097-4687(19970 9)233:3\%3c267:AID-JMOR6\%3e3.0.CO;2-0

Pyron AR, Wiens JJ (2011) A large-scale phylogeny of Amphibia including over 2800 species, and a revised classification of extant frogs, salamanders, and caecilians. Mol Phylogenet Evol 61:543583. https://doi.org/10.1016/j.ympev.2011.06.012

Remane A (1952) Die Grundlagen des natürlichen Systems, der vergleichenden Anatomie und der Phylogenetik. Theorerische Morphologie und Systematik I. Akademische Verlagsgesellschaft Geest and Portig, Leipzig

Ritland RM (1955) Studies on the post-cranial morphology of Ascaphus truei. II Myology. J Morphol 97:215-282. https://doi. org/10.1002/jmor.1050970203

Rolleston G (1869) On the homologies of certain muscles connected with the shoulder-joint. Trans Linn Soc Lond 26:609-629. https ://doi.org/10.1111/j.1096-3642.1869.tb00541.x

Romer AS (1922) The locomotor apparatus of certain primitive and mammal-like reptiles. Bull Am Mus Nat Hist 46:517-606

Romer AS (1924) Pectoral limb musculature and shouldergirdler structure in fish and tetrapods. Anat Rec 27:119-143. https://doi. org/10.1002/ar.1090270210

Schindelin J, Arganda-Carreras I, Frise E, Kaynig V, Longair M, Pietzsch T, Preibisch S, Rueden C, Saalfeld S, Schmid B, Tinevez
J-Y, White DJ, Hartenstein V, Eliceiri K, Tomancak P, Cardona A (2012) Fiji: an open-source platform for biological-image analysis. Nat Methods 9:676-682. https://doi.org/10.1038/nmeth.2019

Schneider CA, Rasband WS, Eliceiri KW (2012) NIH image to ImageJ: 25 years of image analysis. Nat Methods 9:671-675. https://doi. org/10.1038/nmeth.2089

Shearman RM (2005) Growth of the pectoral girdle of the Leopard frog, Rana pipiens (Anura: Ranidae). J Morphol 264:94-104. https://doi.org/10.1002/jmor.10322

Shearman RM (2008) Chondrogenesis and ossification of the lissamphibian pectoral girdle. J Morphol 269:479-495. https://doi. org/10.1002/jmor.10597

Shubin NH, Daeschler EB, Jenkins FA (2006) The pectoral fin of Tiktaalik roseae and the origin of the tetrapod limb. Nature 440:764771. https://doi.org/10.1038/nature04637

Shubin N, Tabin C, Carroll S (2009) Deep homology and the origins of evolutionary novelty. Nature 457:818-823. https://doi. org/10.1038/nature07891

Soliz MC, Ponssa ML, Abdala V (2018) Comparative anatomy and development of pectoral and pelvic girdles in hylid anurans. J Morphol 217:536. https://doi.org/10.1002/jmor.20820

Tyson H (1987) The structure and development of the anuran breastshoulder apparatus, forelimb, and associated musculature. Dissertation, University of Alberta

Zachos FE (2016) Tree thinking and species delimitation: guidelines for taxonomy and phylogenetic terminology. Mamm Biol 81:185188. https://doi.org/10.1016/j.mambio.2015.10.002

Zbären J (1966) Eine Azan-ähnliche Färbung mit Kernechtrubin als Kernfarbstoff. Mikrokosmos 55:286

Publisher's Note Springer Nature remains neutral with regard to jurisdictional claims in published maps and institutional affiliations. 